Article

\title{
Thermal Buckling of Nanocomposite Stiffened Cylindrical Shells Reinforced by Functionally Graded Wavy Carbon Nanotubes with Temperature-Dependent Properties
}

\author{
Mohammad Nejati ${ }^{1}$, Rossana Dimitri ${ }^{2}$, Francesco Tornabene ${ }^{3, *}$ (D) and \\ Mohammad Hossein Yas 4 \\ 1 Young Researchers and Elite Club, Arak Branch, Islamic Azad University, 38137 Arak, Iran; \\ m.nejati313@gmail.com \\ 2 Department of Innovation Engineering, Università del Salento, 73100 Lecce, Italy; \\ rossana.dimitri@unisalento.it \\ 3 Department of Civil, Chemical, Environmental and Materials Engineering (DICAM), University of Bologna, \\ 40136 Bologna, Italy \\ 4 Department of Mechanical Engineering, Razi University, 65571 Kermanshah, Iran; yas@razi.ac.ir \\ * Correspondence: francesco.tornabene@unibo.it
}

Received: 27 October 2017; Accepted: 23 November 2017; Published: 27 November 2017

\begin{abstract}
We study the thermal buckling behavior of cylindrical shells reinforced with Functionally Graded (FG) wavy Carbon NanoTubes (CNTs), stiffened by stringers and rings, and subjected to a thermal loading. The equilibrium equations of the problem are built according to the Third-order Shear Deformation Theory (TSDT), whereas the stiffeners are modeled as Euler Bernoulli beams. Different types of FG distributions of wavy CNTs along the radial direction of the cylinder are herein considered, and temperature-dependent material properties are estimated via a micromechanical model, under the assumption of uniform distribution within the shell and through the thickness. A parametric investigation based on the Generalized Differential Quadrature (GDQ) method aims at investigating the effects of the aspect ratio and waviness index of CNTs on the thermal buckling of FG nanocomposite stiffened cylinders, reinforced with wavy single-walled CNTs. Some numerical examples are here provided in order to verify the accuracy of the proposed formulation and to investigate the effects of several parameters-including the volume fraction, the distribution pattern of wavy CNTs, and the cylinder thickness-on the thermal buckling behavior of the stiffened cylinders made of CNT-reinforced composite (CNTRC) material.
\end{abstract}

Keywords: carbon nanotube; GDQ method; stiffened cylindrical shells; thermal buckling; TSDT

\section{Introduction}

Today, stiffened cylindrical shells are widely used in a variety of engineering systems, including aircraft, spacecraft, submarine, naval, automotive, and civil applications. In particular, attention has been devoted to study the stability of stiffened composite shells and materials that are usually subjected to sever thermal environments and loadings. Many thermal buckling studies of laminated composite shells can be found in the literature, which aim at determining the critical mechanical loading under uniform or non-uniform thermal conditions (see e.g., [1-7] among others). Thus, different analytical and/or numerical formulations have been considered to approach thermal buckling problems of plate and shell structures. A first-order shear deformation theory (FSDT), for example, was applied by Tauchert [8] and Avci et al. [9] to study the buckling behavior of cross-ply laminated hybrid composite laminates under a uniform thermal loading. Meanwhile, Lee [10] studied the thermal 
buckling of composite plates by using a layer-wise theory, whereas Matsunaga [11] solved the same problem by using a global higher order deformation theory. Baruta et al. [12] applied a nonlinear finite element analysis to study the response of moderately thick laminated panels in large deformations under a non-uniform temperature field. A differential quadrature method was adopted by Ghomshei and Mahmoudi [13] to analyze the thermal buckling behavior of symmetric cross-ply laminated rectangular thin plates subjected to a uniform and/or non-uniform thermal loading. More in detail, a parametric study was performed by the authors to investigate the effect of some geometrical and mechanical parameters-including the stiffness ratios, cross-ply ratios, and aspect ratios-on the critical thermal temperature and buckling behavior of thin plates. In the last decades, many optimization problems have also gained much attention for design purposes in order to define the optimal buckling temperature of a composite structure (see [14-19] among others).

However, there is a general lack of information about the thermal buckling behavior of composite plates and shells in presence of CNT reinforcements and/or structural stiffeners. Some preliminary works [20-24], for example, examined the buckling behavior of composite shells reinforced with stiffeners without considering any possible effect related to a thermal loading condition. Moreover, Nejati et al. [25] studied the mechanical buckling behavior of FG cantilever beams while considering the agglomeration effect of CNTs within the structures. Mohammadzadeh et al. [26] analyzed the mechanical buckling of two-dimensional FG cylindrical shells subjected to an axial and pressure loading, according to a classical theory. The effect of temperature distributions on the mechanical properties of Functionally Graded Material (FGM) composites and non-homogeneous materials was also studied in [27-32] while focusing on the presence of fibers or CNTs as reinforcement. Such materials and structures, however, have shown complex thermal buckling behavior due to the large displacements and rotations they can experience in the presence of a generally distributed temperature.

To this end, in the present work, we provide a parametric investigation on the stability of FG wavy CNT stiffened cylindrical shells under a uniform thermal loading, where the materials feature some temperature-dependent properties. More specifically, we discuss about the main effects of nanomaterials and stiffeners on the critical thermal buckling load for CNTRC cylindrical shells with temperature-dependent properties.

The problem is approached numerically with the use of the GDQ method, as successfully applied in the literature for many applications, e.g., buckling problems and free vibrations of FG cantilever beams or shells reinforced with CNTs (see [29,33-37] among others), the dynamics of undamaged and damaged arches with different shapes [38-43], as well as non-linear transient problems [44-50]. In the present work, we verify the ability of the GDQ method to capture the sensitivity of the structural response to the CNT pattern and volume fraction as well as to some geometry parameters. The paper is structured as follows. After this Introduction, we discuss the material properties assumed for the FG-CNTRC cylinders. In Section 3, we present the fundamental equations of the problem, which are solved numerically by means of a GDQ approach, as implemented in Section 4. Section 5 is concerned with the parametric investigation aimed at studying the thermal buckling behavior of the FG-CNTRC cylinders. The final conclusions are drawn in Section 6.

\section{Material Properties in FG-CNTRC Cylinders}

A CNTRC cylindrical shell is considered, with the inner radius $r_{i}$, and the outer radius $r_{o}$, as shown in Figure 1, along with the coordinate system $(x, y, z)$. The cylinder is made of a mixture of wavy single walled CNT (SWCNT) along the radial direction and an isotropic polymer matrix phase. The wavy SWCNT reinforcement is either uniformly distributed (UD) or FG in the radial direction. Thus, we apply the rule of mixture as proposed in the literature by [51] and here modified by introducing an efficiency parameter $\eta^{*}$ in order to account for wavy fibers uniformly dispersed in the polymer matrix phase, namely, the carbon nanotube $(\mathrm{CNT})$ aspect ratio $\left(A_{R}\right)$ and waviness $(w)$. The effective mechanical 
properties for the CNTRC cylindrical shell, obtained according to the micro mechanical model [20], take the following form:

$$
\begin{aligned}
E_{1} & =\eta_{1} V_{C N T} E_{1, \eta *}+V_{m} E^{m} \\
\frac{\eta_{2}}{E_{2}} & =\frac{V_{C N T}}{E_{2, \eta *}}+\frac{V_{m}}{E^{m}} \\
\frac{\eta_{3}}{G_{12}} & =\frac{V_{C N T}}{G_{12, \eta *}}+\frac{V_{m}}{G^{m}} \\
v_{12} & =V_{C N} v_{12}^{C N T}+V_{m} v^{m} \\
\alpha_{11} & =\frac{V_{C N} E_{11}^{C N T} \alpha_{11}^{C N T}+V_{m} E^{m} \alpha_{m}}{V_{C N} E_{11}^{C N}+V_{m} E^{m}} \\
\alpha_{22} & =\left(1+v_{12}^{C N T}\right) V_{C N} \alpha_{22}^{C N T}+\left(1+v^{m}\right) V_{m} \alpha^{m}-v_{12} \alpha_{11}
\end{aligned}
$$

where

$$
\begin{aligned}
& E_{i, \eta *}=\eta^{*} E_{i}^{C N T} \text { for } i=1,2,3 \\
& \eta^{*}=1-\frac{\tanh \left(K A_{R} /(1+\langle c\rangle)\right)}{K A_{R} /(1+\langle c\rangle)} \\
& K=\sqrt{\left(-\frac{2}{1+v_{m}}\right) /\left(\frac{E^{C N}}{E_{m}} \ln \left(V_{C N T}\right)\right)}
\end{aligned}
$$

whereas $E_{1}^{C N T}, E_{2}^{C N T}$ refer to the longitudinal and transverse elastic modulus of the CNT, respectively, and $G_{12}^{C N T}, v_{12}^{C N T}, E_{\eta^{*}},\langle c\rangle$ refer to its shear modulus, Poisson's ratio, effective reinforcement modulus, average number of contacts per particle, respectively.
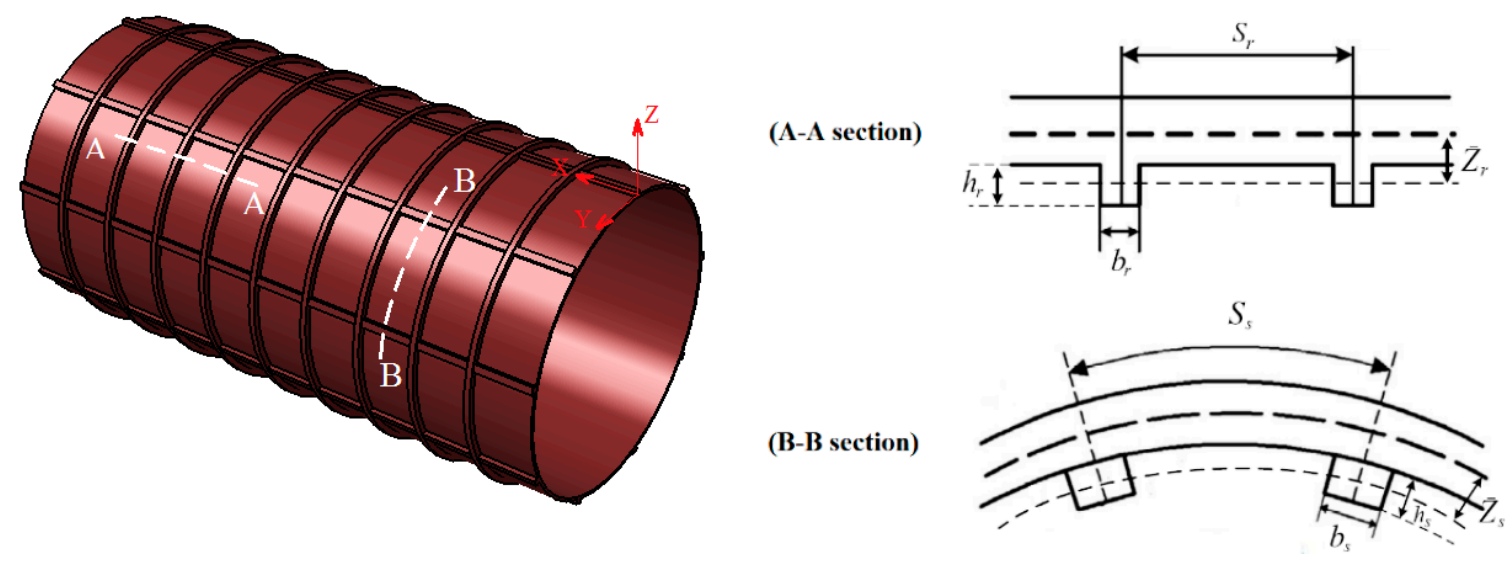

Figure 1. Geometrical scheme of a stiffened cylindrical shell.

The main properties for the matrix are referred to as $E^{m}, G^{m}$ and $v^{m}$ in terms of elastic modulus, shear modulus and Poisson's ratio, respectively. Moreover, $V_{C N T}$ and $V_{m}$ represent the volume fractions of the fiber (CNT) and matrix, respectively, such that $V_{C N T}+V_{m}=1$. We finally define $\eta_{j}(j=1,2,3)$ as the CNT efficiency parameters, which are introduced to account for the size-dependent material properties of the shell. These parameters can be computed combining the elastic modulus of CNTRCs as predicted by the molecular dynamics (MD) and the analytical estimations based on Equation (1). For three different volume fractions CNTs, $V_{C N T}^{*}$, as selected hereafter, the efficiency parameters $\eta_{j}$ assume the following values:

$$
\begin{aligned}
& \eta_{1}=0.137, \eta_{2}=1.022 \text { for } V_{C N T}^{*}=0.12 \\
& \eta_{1}=0.142, \eta_{2}=1.626 \text { for } V_{C N T}^{*}=0.17 \\
& \eta_{1}=0.141, \eta_{2}=1.585 \text { for } V_{C N T}^{*}=0.28 \\
& \eta_{3}=0.7 \eta_{2}
\end{aligned}
$$


The average number $\langle c\rangle$ of contacts per CNT is also defined as a function of the aspect ratio $A_{R}$ and waviness $w$ as follows [51]:

$$
\langle c\rangle=w V_{C N T}\left(4+\frac{3 A_{R}^{2}}{3 A_{R}+2}\right)
$$

which, in turn, accounts for the actual curvature of CNTs within the composite material. The accuracy of our approach is verified against the available literature. It is worth noticing that the approach here considered for the analyses can be commonly applied for the only reinforcing phase made of CNTs with a straight and aligned direction inside the matrix. More complex models, however, could be applied in a further research in order to account for the effect of CNTs agglomeration and waviness on the mechanical properties of the reinforced composite (see e.g., [21]). Different kinds of material profiles are also assumed along the thickness of the shell to examine the effect of the CNT distribution on the thermal buckling behaviour of the FG-CNT cylindrical shell, namely, a uniform $(U)$, an asymmetrical $(\wedge)$, and two symmetric distributions $(X$ and $O$ ) (see [30]).

$$
V_{C N T}(z)= \begin{cases}V_{C N T}^{*} & (U) \\ \left(1-\frac{2 z}{h}\right) V_{C N T}^{*} & (\wedge) \\ \frac{4|z|}{h} V_{C N T}^{*} & (X) \\ 4\left(\frac{1}{2}-\frac{|z|}{h}\right) V_{C N T}^{*} & (O)\end{cases}
$$

$h$ being the thickness of the shell, and $V_{C N T}^{*}$ being the volume fraction of the CNT defined as

$$
V_{C N T}^{*}=\frac{w_{C N T}}{w_{C N T}+\left(\frac{\rho_{C N T}}{\rho_{m}}\right)-\left(\frac{\rho_{C N T}}{\rho_{m}}\right) w_{C N T}}
$$

while $w_{C N T}$ is the mass fraction of the $\mathrm{CNT}, \rho_{\mathrm{CNT}}$ and $\rho_{m}$ are the densities of the CNT and matrix, respectively. In the present work, we also propose a sigmoidal shape as a possible distribution for the CNT volume fraction, i.e.,

$$
V_{C N T}=\frac{e^{s \bar{r}}-1}{\left(e^{s / 2}-1\right)\left(e^{s(\bar{r}-1 / 2)}+1\right)}
$$

in which $\bar{r}=(z+h / 2) / h$ and the exponent $s$ controls the CNT variation profile along the radial direction. This profile changes its sigmoidal shape for varying values of the sigmoid exponent, as depicted in Figure 2. More specifically, when $s=1$, the CNT volume fraction varies linearly from 0 to 1 along the thickness direction. As the sigmoid exponent $s$ increases, the FG shell turns to be a laminated shell with two laminae, whose CNT volume fraction at the inner and outer surfaces are 0 and $V_{C N T}^{*}$, respectively. According to findings by Sobhaniaragh et al. [22], symmetric distributions of CNTs through the thickness of the structure are expected to have higher capabilities to reduce or increase the natural frequency of the structure compared to uniform or asymmetric distributions. 


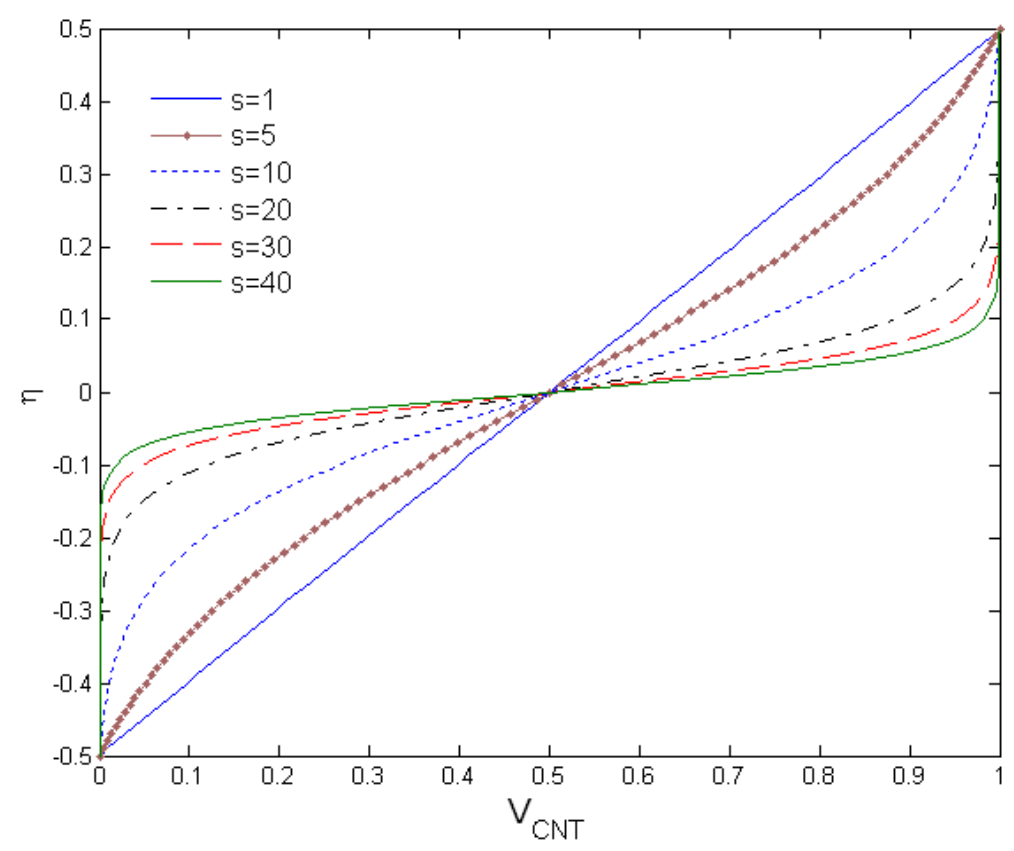

Figure 2. Sigmoidal distributions of the $V_{C N T}$ through the thickness for different exponents $s$. CNT: Carbon NanoTubes.

For a temperature-dependent analysis of thermo-mechanical properties for a $(10,10)$ armchair SWCNT under a varying temperature $300 \mathrm{~K} \leq T \leq 700 \mathrm{~K}$, for example, we apply a third order expansion, as follows [23]:

$$
\begin{aligned}
& E^{m}(\mathrm{GPa})=(3.52-0.0034 \mathrm{~T}) \\
& v^{m}=0.34 \\
& \alpha^{m}=45(1+0.0005 \Delta T) 10^{-6} / \mathrm{K}, \\
& v_{12}^{\mathrm{CNT}}=0.175, \\
& E_{11}^{C N T}(\mathrm{~T})(\mathrm{TPa})=6.3998-4.338417 \times 10^{-3} \mathrm{~T}+7.43 \times 10^{-6} T^{2}-4.458333 \times 10^{-9} T^{3} \\
& E_{22}^{C N T}(T)(\mathrm{TPa})=8.02155-5.420375 \times 10^{-3} T+9.275 \times 10^{-6} T^{2}-5.5625 \times 10^{-9} T^{3} \\
& G_{12}^{C N T}(T)(\mathrm{TPa})=1.40755+3.476208 \times 10^{-3} T-6.965 \times 10^{-6} T^{2}+4.479167 \times 10^{-9} \mathrm{~T}^{3} \\
& \alpha_{11}^{C N}(T)\left(10^{-6} / \mathrm{K}\right)=-1.12515+0.02291688 \mathrm{~T}-2.887 \times 10^{-5} T^{2}+1.13625 \times 10^{-8} \mathrm{~T}^{3} \\
& \alpha_{22}^{C N}(T)\left(10^{-6} / \mathrm{K}\right)=5.43715-0.984625 \times 10^{-4} T+2.9 \times 10^{-7} T^{2}+1.25 \times 10^{-11} \mathrm{~T}^{3}
\end{aligned}
$$

\section{Fundamental Equations}

Based on the TSDT [24], the displacement components $u, v, w$ of the shell along the $x, y, z$-axes (see Figure 1), can be expressed as

$$
\begin{aligned}
& u(x, y, z)=u_{0}(x, y)+z \psi(x, y)+z^{2} \theta_{x}(x, y)+z^{3} \lambda_{x}(x, y) \\
& v(x, y, z)=v_{0}(x, y)+z \phi(x, y)+z^{2} \theta_{y}(x, y)+z^{3} \lambda_{y}(x, y) \\
& w(x, y, z)=w_{0}(x, y)
\end{aligned}
$$

$u_{0}, v_{0}, w_{0}$ being the displacement components of a point belonging to the reference surface of the shell at $z=0$, while $\psi$ and $\phi$ represent its rotations about the $x$ - and $y$-axes, respectively. 
By considering the stress-free conditions on the inner and outer surfaces of the shell, i.e., for $\sigma_{x z}(x, y, \pm h / 2)=\sigma_{y z}(x, y, \pm h / 2)=0$, the relation (8) can be rewritten as

$$
\begin{aligned}
& u(x, y, z)=u_{0}(x, y)+z \psi(x, y)-c_{1} z^{3}\left(\psi+w_{0, x}\right) \\
& v(x, y, z)=v_{0}(x, y)+z \phi(x, y)-c_{1} z^{3}\left(\phi+w_{0, y}\right) \\
& w(x, y, z)=w_{0}(x, y)
\end{aligned}
$$

where $c_{1}=-4 / 3 h^{2}$. The following nonlinear strain-displacement expressions can be determined as

$$
\begin{aligned}
& \left\{\begin{array}{l}
\varepsilon_{x x} \\
\varepsilon_{y y} \\
\gamma_{x y}
\end{array}\right\}=\left\{\begin{array}{c}
\varepsilon_{x x}^{(0)} \\
\varepsilon_{y y}^{(0)} \\
\gamma_{x y}^{(0)}
\end{array}\right\}+z\left\{\begin{array}{c}
\varepsilon_{x x}^{(1)} \\
\varepsilon_{y y}^{(1)} \\
\gamma_{x y}^{(1)}
\end{array}\right\}+z^{3}\left\{\begin{array}{c}
\varepsilon_{x x}^{(3)} \\
\varepsilon_{y y}^{(3)} \\
\gamma_{x y}^{(3)}
\end{array}\right\} \\
& \left\{\begin{array}{l}
\gamma_{x z} \\
\gamma_{y z}
\end{array}\right\}=\left\{\begin{array}{l}
(0) \\
\gamma_{x z}^{(0)} \\
\gamma_{y z}^{(0)}
\end{array}\right\}+z^{2}\left\{\begin{array}{c}
(2) \\
\gamma_{x z}^{(2)} \\
\gamma_{y z}^{(2)}
\end{array}\right\}
\end{aligned}
$$

with

$$
\begin{aligned}
& \left\{\begin{array}{l}
\varepsilon_{x x}^{(0)} \\
\varepsilon_{y y}^{(0)} \\
\gamma_{x y}^{(0)}
\end{array}\right\}=\left\{\begin{array}{l}
u_{0, x}+w_{0, x}^{2} / 2 \\
v_{0, y}+w / R+w_{0, y}^{2} / 2 \\
u_{0, y}+v_{0, x}+w_{0, x} w_{0, y}
\end{array}\right\} \\
& \left\{\begin{array}{l}
\varepsilon_{x x}^{(1)} \\
\varepsilon_{y y}^{(1)} \\
\gamma_{x y}^{(1)}
\end{array}\right\}=\left\{\begin{array}{l}
\psi_{, x} \\
\phi_{, y} \\
\psi_{, y}+\phi, x
\end{array}\right\} \\
& \left\{\begin{array}{l}
\varepsilon_{x x}^{(3)} \\
\varepsilon_{y y}^{(3)} \\
\gamma_{x y}^{(3)}
\end{array}\right\}=-c_{1}\left\{\begin{array}{l}
\psi_{, x}+w_{0, x x} \\
\phi_{, y}+w_{0, y y} \\
\psi_{, y}+\phi_{, x}+2 w_{0, x y}
\end{array}\right\} \\
& \left\{\begin{array}{l}
\gamma_{x z}^{(2)} \\
\gamma_{y z}^{(2)}
\end{array}\right\}=-3 c_{1}\left\{\begin{array}{l}
\psi+w_{0, x} \\
\phi+w_{0, y}
\end{array}\right\} \\
& \left\{\begin{array}{l}
\gamma_{x z}^{(0)} \\
\gamma_{y z}^{(0)}
\end{array}\right\}=\left\{\begin{array}{l}
\psi+w_{0, x} \\
\phi+w_{0, y}
\end{array}\right\}
\end{aligned}
$$

In the above relations (10) and (11), $\varepsilon_{x x}$ and $\varepsilon_{y y}$ refer to the normal strains, whereas $\gamma_{x y}, \gamma_{x z}$ and $\gamma_{y z}$ refer to the shear strains. The constitutive relations defining a linear thermos-elastic material can be expressed as a linear function of the strain field and the temperature variation, namely

$$
\left\{\begin{array}{l}
\sigma_{x x} \\
\sigma_{y y} \\
\tau_{y z} \\
\tau_{x z} \\
\tau_{x y}
\end{array}\right\}=\left[\begin{array}{ccccc}
Q_{11} & Q_{12} & 0 & 0 & 0 \\
Q_{21} & Q_{22} & 0 & 0 & 0 \\
0 & 0 & Q_{44} & 0 & 0 \\
0 & 0 & 0 & Q_{55} & 0 \\
0 & 0 & 0 & 0 & Q_{66}
\end{array}\right]\left\{\begin{array}{l}
\varepsilon_{x x}-\alpha_{11} \Delta T \\
\varepsilon_{y y}-\alpha_{22} \Delta T \\
\gamma_{y z} \\
\gamma_{x z} \\
\gamma_{x y}
\end{array}\right\}
$$


where $\Delta T=T-T_{0}$ and $T$ and $T_{0}$ refer to a varied temperature and a reference temperature, respectively. In addition, the elastic coefficients $Q_{i j}($ for $i, j=1, \ldots, 6)$ are the reduced material stiffness coefficients compatible with the plane-stress conditions. They are obtained as follow [52-54]

$$
\begin{aligned}
& Q_{11}=\frac{E_{11}(z, T)}{1-v_{12}(z, T) v_{21}(z, T)}, \\
& Q_{22}=\frac{E_{22}(z, T)}{1-v_{12}(z, T) v_{21}(z, T)}, \\
& Q_{12}=\frac{v_{21}(z, T) E_{11}(z, T)}{1-v_{12}(z, T) v_{21}(z, T)}, \\
& Q_{44}=G_{23}(z, T) \\
& Q_{55}=G_{13}(z, T) \\
& Q_{66}=G_{12}(z, T)
\end{aligned}
$$

The equilibrium equations for a FG wavy CNTRC stiffened cylindrical shell under thermal loading will be derived from a stationary potential energy criterion. Thus, we define the total potential energy for a cylindrical shell stiffened by ring and stiffeners as

$$
U=U_{S h}+U_{r}+U_{s}
$$

where $U_{S h}, U_{r}, U_{s}$ are the single components of the strain energy for the shell, the ring, and the stiffeners, respectively. More specifically, according to the TSDT, the strain energy component $U_{S h}$ for the cylindrical shell can be defined as

$$
\begin{aligned}
U_{s h}=\frac{1}{2} \int_{V}\left\{\sigma_{x x}\left(\varepsilon_{x x}^{(0)}+z \varepsilon_{x x}^{(1)}+z^{3} \varepsilon_{x x}^{(3)}\right)+\sigma_{y y}\left(\varepsilon_{y y}^{(0)}+z \varepsilon_{y y}^{(1)}+Z^{3} \varepsilon_{y y}^{(3)}\right)+\right. \\
\left.\tau_{x y}\left(\gamma_{x y}^{(0)}+z \gamma_{x y}^{(1)}+z^{3} \gamma_{x y}^{(3)}\right)+\tau_{x z}\left(\gamma_{x z}^{(0)}+z^{2} \gamma_{x z}^{(2)}\right)+\tau_{y z}\left(\gamma_{y z}^{(0)}+z^{2} \gamma_{y z}^{(2)}\right)\right\} d V
\end{aligned}
$$

As is different from the available works [55,56], where the discrete stiffener are smeared out over the respective spacing, in the present paper, we model the stiffeners as Euler-Bernoulli beams under the hypothesis that normals to the cylindrical shell and stiffeners remain normal after the deflection. Thus, following the Kirchhoff-Love classical assumptions [52] the displacement field can be expressed as

$$
\begin{aligned}
& \bar{u}(x, y)=u_{I}(x, y)-z \frac{\partial w_{I}(x, y)}{\partial x} \\
& \bar{v}(x, y)=v_{I}(x, y)-z \frac{\partial w_{I}(x, y)}{\partial y} \\
& \bar{w}(x, y)=w_{I}(x, y)
\end{aligned}
$$

where $u_{I}, v_{I}$, and $w_{I}$ denote the displacement components of points located through the cylindrical shell thickness. The following expressions for the strain field $\varepsilon_{s}, \varepsilon_{r}$ are derived for stringer and ring stiffeners, respectively:

$$
\begin{aligned}
& \varepsilon_{s}=\frac{\partial u_{I}}{\partial x}+\frac{1}{2}\left(\frac{\partial w_{I}}{\partial x}\right)^{2}-z \frac{\partial^{2} w_{I}}{\partial x^{2}} \\
& \varepsilon_{r}=\frac{\partial v_{I}}{\partial y}+\frac{1}{2}\left(\frac{\partial w_{I}}{\partial y}\right)^{2}+\frac{w_{I}}{R}-z\left(\frac{\partial^{2} w_{I}}{\partial y^{2}}\right)
\end{aligned}
$$

Moreover, we propose the following form to define the stress field of stringer and ring stiffeners in thermal environments (see $[57,58])$.

$$
\begin{aligned}
& \bar{\sigma}_{x x}=E_{s} \varepsilon_{s}-\frac{E_{s}}{1-2 v_{s}} \alpha_{s}(z, T) \Delta T \\
& \bar{\sigma}_{y y}=E_{r} \varepsilon_{r}-\frac{E_{r}}{1-2 v_{r}} \alpha_{r}(z, T) \Delta T
\end{aligned}
$$

$E_{s}, E_{r}$ being the elasticity modulus for stringer and ring stiffeners, respectively. More complex models could be considered to capture the actual orthotropic behavior of stiffeners or ribs, as proposed in [59]. 
This will be considered as a further development of the proposed formulation, here explored in a simplified manner. Based on our formulation, the corresponding strain energy is expressed as [52]

$$
\begin{aligned}
& \delta U_{s}=\frac{1}{S_{s}} \int_{0}^{L} \int_{0}^{\alpha}\left(\int_{A_{s}} \sigma_{s} \delta \varepsilon_{s} d A+G_{s} J_{s} \frac{\partial^{2} w_{I}}{\partial x \partial y} \frac{\partial^{2} \delta w_{I}}{\partial x \partial y}\right) d y d x \\
& \delta U_{r}=\frac{1}{S_{r}} \int_{0}^{L} \int_{0}^{\alpha}\left(\int_{A_{r}} \sigma_{r} \delta \varepsilon_{r} d A+G_{r} J_{r} \frac{\partial^{2} w_{I}}{\partial x \partial y} \frac{\partial^{2} \delta w_{I}}{\partial x \partial y}\right) d y d x
\end{aligned}
$$

Substituting Equations (17) and (18) into Equation (19), it is

$$
\left.\begin{array}{c}
\delta U_{s}=\int_{\Omega} \frac{1}{S_{s}}\left\{\left(\begin{array}{l}
E_{s} A_{s}\left(\frac{\partial u_{I}}{\partial x}+\frac{1}{2}\left(\frac{\partial w_{I}}{\partial x}\right)^{2}-\frac{\alpha_{s} \Delta T}{1-2 v_{s}}\right)\left(\frac{\partial \delta u_{I}}{\partial x}+\frac{\partial w_{I}}{\partial x} \frac{\partial \delta w_{I}}{\partial x}\right)+ \\
-E_{s} A_{s} \bar{z}_{s} \frac{\partial^{2} \delta w_{I}}{\partial x^{2}}\left(\frac{\partial u_{I}}{\partial x}+\frac{1}{2}\left(\frac{\partial w_{I}}{\partial x}\right)^{2}-\frac{\alpha_{s} \Delta T}{1-2 v_{s}}\right)+ \\
-E_{s} A_{s} \bar{z}_{s} \frac{\partial^{2} w_{I}}{\partial x^{2}}\left(\frac{\partial \delta u_{I}}{\partial x}+\frac{\partial w_{I}}{\partial x} \frac{\partial \delta w_{I}}{\partial x}\right)+E_{s} I_{s} \frac{\partial^{2} w_{I}}{\partial x^{2}} \frac{\partial^{2} \delta w_{I}}{\partial x^{2}}
\end{array}\right)+G_{s} J_{s} \frac{\partial^{2} w_{I}}{\partial x \partial \theta} \frac{\partial^{2} \delta w_{I}}{\partial x \partial \theta}\right.
\end{array}\right) d x d \theta
$$

$I_{r}=b_{r} h_{r}{ }^{3} / 12+\bar{z}_{r}^{2} A_{r}$ and $I_{s}=b_{s} h_{s}{ }^{3} / 12+\bar{z}_{s}^{2} A_{s}$ being the moments of inertia for the rings and stringers at a distance $\bar{z}_{r}, \bar{z}_{s}$ from the reference surface $(z=0)$, with cross sections $A_{r}, A_{s}$, heights $h_{r}, h_{s}$, and widths $b_{r}, b_{s}$. Besides, $J_{s}=h_{s} b_{s}{ }^{3} / 3$ and $J_{r}=h_{r} b_{r}{ }^{3} / 3$ are the polar moments of inertia of the rings and stringers, while $S_{s}=2 \pi R / N_{s}, S_{r}=L / N_{r}$ refer to the distances between two consecutive stringers and rings, whose total number is $N_{s}$ and $N_{r}$, respectively.

Furthermore, the internal actions of the cylindrical shell can be expressed in terms of forces and moments as follows:

$$
\begin{array}{ll}
\left(N_{i j}, M_{i j}, P_{i j}\right)=\int_{-h / 2}^{h / 2} \sigma_{i j}\left(1, z, z^{3}\right) d z & i j=x x, y y \\
\left(N_{i j}, M_{i j}, P_{i j}\right)=\int_{-h / 2}^{h / 2} \sigma_{i j}\left(1, z, z^{3}\right) d z & i j=x y \\
\left(Q_{i j}, R_{i j}\right)=\int_{-h / 2}^{h / 2} \sigma_{i j}\left(1, z^{2}\right) d z & i j=x z, y z
\end{array}
$$

Using the Equations (11), (12) and (22), the internal actions for the FG-CNTRC stiffened cylindrical shell become

$$
\begin{aligned}
& N_{x x}=A_{11} \varepsilon_{x x}^{(0)}+A_{22} \varepsilon_{x x}^{(1)}+A_{44} \varepsilon_{x x}^{(3)}+B_{11} \varepsilon_{y y}^{(0)}+B_{22} \varepsilon_{y y}^{(1)}+B_{44} \varepsilon_{y y}^{(3)} \\
& N_{y y}=B_{11} \varepsilon_{x x}^{(0)}+B_{22} \varepsilon_{x x}^{(1)}+B_{44} \varepsilon_{x x}^{(3)}+D_{11} \varepsilon_{y y}^{(0)}+D_{22} \varepsilon_{y y}^{(1)}+D_{44} \varepsilon_{y y}^{(3)} \\
& N_{x y}=E_{11} \gamma_{x y}^{(0)}+E_{22} \gamma_{x y}^{(1)}+E_{44} \gamma_{x y}^{(3)} \\
& P_{x x}=A_{44} \varepsilon_{x x}^{(0)}+A_{55} \varepsilon_{x x}^{(1)}+A_{77} \varepsilon_{x x}^{(3)}+B_{44} \varepsilon_{y y}^{(0)}+B_{55} \varepsilon_{y y}^{(1)}+B_{77} \varepsilon_{y y}^{(3)} \\
& P_{y y}=B_{44} \varepsilon_{x x}^{(0)}+B_{55} \varepsilon_{x x}^{(1)}+B_{77} \varepsilon_{x x}^{(3)}+D_{44} \varepsilon_{y y}^{(0)}+D_{55} \varepsilon_{y y}^{(1)}+D_{77} \varepsilon_{y y}^{(3)} \\
& P_{x y}=E_{44} \gamma_{x y}^{(0)}+E_{55} \gamma_{x y}^{(1)}+E_{77} \gamma_{x y}^{(3)} \\
& M_{x x}=A_{22} \varepsilon_{x x}^{(0)}+A_{33} \varepsilon_{x x}^{(1)}+A_{55} \varepsilon_{x x}^{(3)}+B_{22} \varepsilon_{y y}^{(0)}+B_{33} \varepsilon_{y y}^{(1)}+B_{55} \varepsilon_{y y}^{(3)} \\
& M_{y y}=B_{22} \varepsilon_{x x}^{(0)}+B_{33} \varepsilon_{x x}^{(1)}+B_{55} \varepsilon_{x x}^{(3)}+D_{22} \varepsilon_{y y}^{(0)}+D_{33} \varepsilon_{y y}^{(1)}+D_{55} \varepsilon_{y y}^{(3)} \\
& M_{x y}=E_{22} \gamma_{x y}^{(0)}+E_{33} \gamma_{x y}^{(1)}+E_{55} \gamma_{x y}^{(3)} \\
& Q_{x z}=F_{11} \gamma_{x z}^{(0)}+F_{33} \gamma_{x z}^{(2)} \\
& Q_{y z}=H_{11} \gamma_{y z}^{(0)}+H_{33} \gamma_{y z}^{(2)} \\
& R_{x z}=F_{33} \gamma_{x z}^{(0)}+F_{55} \gamma_{x z}^{(2)} \\
& R_{y z}=H_{33} \gamma_{y z}^{(0)}+H_{55} \gamma_{y z}^{(2)}
\end{aligned}
$$


where the constants are determined as

$$
\begin{aligned}
& \left(A_{11}, A_{22}, A_{33}, A_{44}, A_{55}, A_{77}\right)=\int_{-h / 2}^{h / 2} Q_{11}(z, T)\left(1, z, z^{2}, z^{3}, z^{4}, z^{6}\right) d z \\
& \left(D_{11}, D_{22}, D_{33}, D_{44}, D_{55}, D_{77}\right)=\int_{-h / 2}^{h / 2} Q_{22}(z, T)\left(1, z, z^{2}, z^{3}, z^{4}, z^{6}\right) d z \\
& \left(B_{11}, B_{22}, B_{33}, B_{44}, B_{55}, B_{77}\right)=\int_{-h / 2}^{h / 2} Q_{12}(z, T)\left(1, z, z^{2}, z^{3}, z^{4}, z^{6}\right) d z \\
& \left(H_{11}, H_{22}, H_{33}, H_{44}, H_{55}, H_{66}\right)=\int_{-h / 2}^{h / 2} Q_{44}(z, T)\left(1, z, z^{2}, z^{3}, z^{4}, z^{5}\right) d z \\
& \left(E_{11}, E_{22}, E_{33}, E_{44}, E_{55}, E_{66}, E_{77}\right)=\int_{-h / 2}^{h / 2} Q_{66}(z, T)\left(1, z, z^{2}, z^{3}, z^{4}, z^{5}, z^{6}\right) d z \\
& \left(F_{11}, F_{33}, F_{55}\right)=\int_{-h / 2}^{h / 2} Q_{55}(z, T)\left(1, z^{2}, z^{4}\right) d z
\end{aligned}
$$

By substitution of Equations (15), (20) and (21) into Equation (14), the equilibrium equation for the FG wavy CNT stiffened cylindrical shell can be obtained with a variational approach. Thus, the adoption of the Euler equation [60] yields to the following set of equilibrium equations

$$
\begin{gathered}
N_{x x, x}+N_{x y, y}+\frac{\partial}{\partial x}\left(\frac{1}{S_{s}}\left(E_{s} A_{s}\left(\frac{\partial u_{I}}{\partial x}+\frac{1}{2}\left(\frac{\partial u_{I}}{\partial x}\right)^{2}\right)-\bar{z}_{s} A_{S} E_{S}\left(\frac{\partial w_{I}}{\partial x}\right)^{2}\right)\right)=0 \\
N_{x y, x}+N_{y y, y}+\frac{\partial}{\partial y}\left(\frac{1}{S_{r}}\left(E_{r} A_{r}\left(\frac{\partial v_{I}}{\partial y}+\frac{w_{I}}{R}+\frac{1}{2}\left(\frac{\partial w_{I}}{\partial y}\right)^{2}\right)-\bar{z}_{r} A_{r} E_{r}\left(\frac{\partial^{2} W_{I}}{\partial y^{2}}\right)\right)\right)=0 \\
-\frac{1}{R} N_{y y}-\frac{1}{R S_{r}}\left(E_{r} A_{r}\left(\frac{\partial v_{I}}{\partial y}+\frac{w_{I}}{R}+\frac{1}{2}\left(\frac{\partial w_{I}}{\partial y}\right)^{2}\right)-\bar{z}_{r} A_{r} E_{r}\left(\frac{\partial^{2} w_{I}}{\partial y^{2}}\right)\right)+N_{x x} w_{0, x x} \\
+N_{y y} w_{0, y y}+2 N_{x y} w_{0, x y}-N_{0 y} \frac{\partial^{2} w}{\partial y^{2}}+\frac{1}{S_{s}} \bar{N}_{x x} \frac{\partial^{2} w_{I}}{\partial x^{2}} \\
-N_{0 x} \frac{\partial^{2} w}{\partial x^{2}}+\frac{1}{S_{r}} \bar{N}_{y y} \frac{\partial^{2} w_{I}}{\partial y^{2}}+Q_{x z, x}+Q_{y z, y}-3 c_{1}\left(R_{x z, x}+R_{y z, y}\right) \\
+c_{1}\left(P_{x x, x x}+2 P_{x y, x y}+P_{y y, y y}\right)-\frac{\partial^{2}}{\partial x^{2}}\left(\frac { 1 } { S _ { s } } \left(\left(E_{s} I_{s}+\bar{z}_{s} E_{s} A_{s} c_{1}\left(\frac{h}{2}\right)^{3}\right) \frac{\partial^{2} w_{I}}{\partial x^{2}}\right.\right. \\
\left.\left.-\left(\bar{z}_{s} A_{s} E_{S}+E_{S} A_{s} c_{1}\left(\frac{h}{2}\right)^{3}\right)\left(\frac{\partial u_{I}}{\partial x}+\frac{1}{2}\left(\frac{\partial w_{I}}{\partial x}\right)^{2}\right)\right)\right)-\frac{\partial^{2}}{\partial y^{2}}\left(\frac { 1 } { S _ { r } } \left(\left(E_{r} I_{r}+\bar{z}_{r} E_{r} A_{r} c_{1}\left(\frac{h}{2}\right)^{3}\right) \frac{\partial^{2} w_{I}}{\partial y^{2}}\right.\right. \\
\left.\left.-\left(\bar{z}_{r} A_{r} E_{r}+E_{r} A_{r} c_{1}\left(\frac{h}{2}\right)^{3}\right)\left(\frac{\partial v_{I}}{\partial y}+\frac{1}{2}\left(\frac{\partial w_{I}}{\partial y}\right)^{2}+\frac{w_{I}}{R}\right)\right)\right)-\frac{\partial^{2}}{\partial x \partial y}\left(\frac{1}{S_{s}} G_{s} J_{s} \frac{\partial^{2} w_{I}}{\partial x \partial y}+\frac{1}{S_{r}} G_{r} J_{r} \frac{\partial^{2} w_{I}}{\partial x \partial y}\right)=0 \\
-Q_{x z}^{1}-3 c_{1} R_{x z}^{1}+M_{x x, x}^{1}+M_{x y, y}^{1}-c_{1}\left(P_{x x, x}^{1}+P_{x y, y}^{1}\right)=0 \\
-Q_{y z}^{1}-3 c_{1} R_{y z}^{1}+M_{x y, x}^{1}+M_{y y \cdot y}^{1}-c_{1}\left(P_{x y, x}^{1}+P_{y y, y}^{1}\right)=0
\end{gathered}
$$

where $\bar{N}_{x x}$ and $\bar{N}_{y y}$ are the axial forces applied to the ring and stringer stiffeners, defined as

$$
\begin{gathered}
\bar{N}_{x x}=\int_{A_{S}} \sigma_{x x} d A=\int_{h / 2}^{h / 2+h_{s}} b_{s} \sigma_{s} d A=E_{s} A_{s}\left(\frac{\partial u_{I}}{\partial x}+\frac{1}{2}\left(\frac{\partial w_{I}}{\partial x}\right)^{2}\right)-\bar{z}_{s} A_{s} E_{s} \frac{\partial^{2} w_{I}}{\partial x^{2}} \\
\bar{N}_{y y}=\int_{A_{S}} \sigma_{y y} d A=\int_{h / 2}^{h / 2+h_{r}} b_{r} \sigma_{r} d A=E_{r} A_{r}\left(\frac{\partial v_{I}}{\partial y}+\frac{1}{2}\left(\frac{\partial w_{I}}{\partial y}\right)^{2}+\frac{w_{I}}{R}\right)-\bar{z}_{r} A_{r} E_{r} \frac{\partial^{2} w_{I}}{\partial y^{2}}
\end{gathered}
$$

By using the Taylor series, the total strain energy of the shell can be expanded about the equilibrium state as

$$
\Delta U=\delta U+\frac{1}{2} \delta^{2} U+\frac{1}{6} \delta^{3} U+\ldots
$$

where the first variation, $\delta U$, is related to the equilibrium configuration. The stability condition of the stiffened cylindrical shell near the equilibrium state is known to be related to the sign of the second 
variation $\delta^{2} U$. The condition $\delta^{2} U=0$ is enforced to determine the stability equations of the buckling problem [60]. To proceed with the stability equations of the CNTRC stiffened cylindrical shell, the displacement components can be written as

$$
u_{0}=u_{0}^{0}+u_{0}^{1}, \quad v_{0}=v_{0}^{0}+v_{0}^{1}, \quad w_{0}=w_{0}^{0}+w_{0}^{1}, \quad \psi=\psi^{0}+\psi^{1}, \quad \phi=\phi^{0}+\phi^{1}
$$

where $u_{0}^{0}, v_{0}^{0}, w_{0}^{0}, \psi^{0}, \phi^{0}$ represent the displacement components at the equilibrium configuration. The displacement fields near the stable equilibrium are expressed by $u_{0}^{1}, v_{0}^{1}, w_{0}^{1}, \psi^{1}, \phi^{1}$. Similarly, the stress resultants associated with the equilibrium condition read

$$
\begin{array}{lll}
N^{1} x x \rightarrow N^{0}{ }_{x x}+\Delta N_{x x} & M^{1}{ }_{x x} \rightarrow M^{0}{ }_{x x}+\Delta M_{x x} & P^{1}{ }_{x x} \rightarrow P^{0}{ }_{x x}+\Delta P_{x x} \\
N^{1}{ }_{y y} \rightarrow N^{0}{ }_{y y}+\Delta N_{y y} & M^{1}{ }_{y y} \rightarrow M^{0}{ }_{y y}+\Delta M_{y y} & P^{1}{ }_{y y} \rightarrow P^{0}{ }_{y y}+\Delta P_{y y} \\
N^{1}{ }_{x y} \rightarrow N^{0}{ }_{x y}+\Delta N_{x y} & M^{1}{ }_{x y} \rightarrow M^{0}{ }_{x y}+\Delta M_{x y} & P^{1}{ }_{x y} \rightarrow P^{0}{ }_{x y}+\Delta P_{x y} \\
Q^{1}{ }_{x z} \rightarrow Q^{0}{ }_{x z}+\Delta Q z & R^{1}{ }_{x z} \rightarrow R^{0}{ }_{x z}+\Delta R_{x z} & \bar{N}^{1}{ }_{x x} \rightarrow \bar{N}_{x x}^{0}+\Delta \bar{N}_{x x} \\
Q^{1}{ }_{y z} \rightarrow Q^{0}{ }_{y z}+\Delta Q_{y z} & R^{1}{ }_{y z} \rightarrow R^{0}{ }_{y z}+\Delta R_{y z} & \bar{N}^{1}{ }_{y y} \rightarrow \bar{N}^{0}{ }_{y y}+\Delta \bar{N}_{y y}
\end{array}
$$

The superscripts 0 and 1 refer to the equilibrium and the stability states, respectively. It is also worth noticing that the applied load enforced at a certain configuration corresponds to the critical buckling load if the relation $\delta^{2} U=0$ is satisfied. By substitution of Equations (11) and (12) into Equation (32) and by combination with Equation (14), we obtain the second variation of the total potential energy, which leads to the stability equations after some mathematical manipulations, i.e.,

$$
\begin{gathered}
N_{x x, x}^{1}+N_{x y, y}^{1}+\frac{\partial}{\partial x}\left(\frac{1}{S_{s}}\left(E_{s} A_{s} \frac{\partial u_{I}^{1}}{\partial x}-\bar{z}_{s} A_{s} E_{s} \frac{\partial^{2} w_{I}^{1}}{\partial x^{2}}\right)\right)=0 \\
N_{x y, x}^{1}+N_{y y, y}^{1}+\frac{\partial}{\partial y}\left(\frac{1}{S_{r}}\left(E_{r} A_{r}\left(\frac{\partial v_{I}^{1}}{\partial y}+\frac{w_{I}^{1}}{R}\right)-\bar{z}_{r} A_{r} E_{r} \frac{\partial^{2} w_{I}^{1}}{\partial y^{2}}\right)\right)=0 \\
\frac{1}{R} N_{y y}^{1}-\frac{1}{R S_{r}}\left(E_{r} A_{r}\left(\frac{\partial v_{I}^{1}}{\partial y}+\frac{w_{I}^{1}}{R}\right)-\bar{z}_{r} A_{r} E_{r} \frac{\partial^{2} w_{I}^{1}}{\partial y^{2}}\right) \\
+N_{x x}^{0} w_{1, x x}+2 N_{x y}^{0} w_{1, x y}+\frac{1}{S_{s}} \bar{N}_{x x}^{0} \frac{\partial^{2} w_{I}^{1}}{\partial x^{2}}+\frac{1}{S_{r}} \bar{N}_{y y}^{0} \frac{\partial^{2} w_{I}^{1}}{\partial y^{2}}-N_{S}^{0} w_{1, x x}-N_{r}^{0} w_{1, y y} \\
+N_{y y}^{0} w_{1, y y}+Q_{x z, x}^{1}+Q_{y z, y}^{1}-3 c_{1}\left(R_{z x, x}^{1}+R_{y z, y}^{1}\right)+c_{1}\left(P_{x x, x x}^{1}+2 P_{x y, x y}^{1}+P_{y y, y y}^{1}\right) \\
-\frac{\partial^{2}}{\partial x^{2}}\left(\frac{1}{S_{s}}\left(E_{s} I_{s} \frac{\partial^{2} w_{I}^{1}}{\partial x^{2}}-\bar{z}_{s} A_{s} E_{s} \frac{\partial u_{I}^{1}}{\partial x}\right)\right) \\
-\frac{\partial^{2}}{\partial y^{2}}\left(\frac{1}{S_{r}}\left(E_{r} I_{r} \frac{\partial^{2} w_{I}^{1}}{\partial y^{2}}-\bar{z}_{r} A_{r} E_{r}\left(\frac{\partial v_{I}^{1}}{\partial y}+\frac{w_{I}^{1}}{R}\right)\right)\right) \\
-\frac{\partial^{2}}{\partial x \partial y}\left(\frac{1}{S_{s}} G_{s} J_{s} \frac{\partial^{2} w_{I}^{1}}{\partial x \partial y}+\frac{1}{S_{r}} G_{r} J_{r} \frac{\partial^{2} w_{I}^{1}}{\partial x \partial y}\right)=0 \\
-Q_{x z}^{1}-3 c_{1} R_{x z}^{1}+M_{x x, x}^{1}+M_{x y, y}^{1}-c_{1}\left(P_{x x, x}^{1}+P_{x y, y}^{1}\right)=0 \\
-Q_{y z}^{1}-3 c_{1} R_{y z}^{1}+M_{x y, x}^{1}+M_{y y, y}^{1}-c_{1}\left(P_{x y, x}^{1}+P_{y y, y}^{1}\right)=0
\end{gathered}
$$


Let consider now a uniform temperature which increases gradually by $\Delta T$. Under this thermal loading condition, the static quantities $N_{x y}^{0}, N_{y y}^{0}, N_{x x}^{0}, N_{s}^{0}, N_{r}^{0}$ defining the pre-buckling forces of the cylindrical shell, are expressed as

$$
\begin{aligned}
& N_{x x}^{0}=-\int_{-h / 2}^{h / 2}\left(Q_{11}(z, T) \alpha_{11}(z, T)+Q_{12}(z, T) \alpha_{22}(z, T)\right) \Delta T d z \\
& N_{s}^{0}=-\frac{A_{s} E_{s}}{S_{s}\left(1-2 v_{s}\right)} \alpha_{s}(T) \Delta T \\
& N_{r}^{0}=-\frac{A_{r} E_{r}}{S_{r}\left(1-2 v_{r}\right)} \alpha_{r}(T) \Delta T \\
& N_{y y}^{0}=N_{x y}^{0}=\bar{N}_{x x}^{0}=\bar{N}_{y y}^{0}=0
\end{aligned}
$$

\section{Numerical Study of the Buckling Behaviour}

Let us consider a stiffened cylindrical shell simply supported at both ends, i.e.,

$$
v_{0}^{1}=w_{0}^{1}=M_{x x}^{1}=N_{x x}{ }^{1}=\phi^{1}=0 \text { at } x=0, L
$$

To solve the stability equations of the stiffened cylinder under a thermal loading, we start considering the approximate solution of the displacement field, defined as product of the unknown functions along the axial direction and the well-known harmonic functions along the circumferential directions as follow (see also [61]):

$$
\begin{aligned}
& u_{1}=u_{0 n}(x) \sin \left(\frac{n y}{R}\right) \\
& v_{1}=v_{0 n}(x) \cos \left(\frac{n y}{R}\right) \\
& w_{1}=w_{0 n}(x) \sin \left(\frac{n y}{R}\right) \\
& \psi_{1}=\psi_{n}(x) \sin \left(\frac{n y}{R}\right) \\
& \phi_{1}=\phi_{n}(x) \cos \left(\frac{n y}{R}\right)
\end{aligned}
$$

where $n=1,2, \ldots$ is the number of half waves in $y$-direction. At this step, we obtain the partial derivatives by substitution of Equation (42) into Equations (35)-(39). These derivatives are here computed in discrete form by applying the GDQ method, whose basic notions and aspects related to its computational cost, accuracy, and numerical stability are discussed in [62-65] in extensive form and are here briefly reviewed before solving the problem. According to the GDQ method, the $j$ th order of derivative can be discretized as a weighted linear sum of the functional values at some fixed nodes according to the following expression:

$$
\left.\frac{d^{j} f(x)}{d x^{j}}\right|_{x=x_{l}}=\sum_{k=1}^{M} \xi_{l k}^{(j)} f\left(x_{k}\right), \quad k=1,2, \ldots, M
$$

where $\xi_{l k}^{(j)}$ are the weighting coefficients determined as in [66,67]. A key point for a successful application of the GDQ method is dictated by the best placement of grid points within the domain. Despite the simplest choice of grid points seems to be represented by an equally-spaced distribution of points in the coordinate direction, non-uniform grid distributions have demonstrated in the literature to yield better results [62]. Based on the comparative assessment performed by Quan and Chang [68] about the numerical performances of some widely-used non-uniform meshes, the Chebyshev polynomials of the first kind was considered as the best choice of discretization. The Chebyshev-Gauss-Lobatto (CGL) grid distribution was applied by Shu [62], whose choice was verified to give better results than the zeros of Chebyshev and Legendre polynomials. Moreover, Bert and Malik [69] highlighted the strict dependence of the best distribution choice of grid points to the analysed problem, and relied on the efficiency of the CGL grids for structural mechanics computations. With Lagrange interpolating polynomials, the CGL sampling point rule was verified to be efficient 
for numerical reasons [70]. Thus, a CGL distribution of grid points has been herein selected for our numerical computations, where a general coordinate $x_{k}$ is expressed as

$$
x_{k}=\left(1-\cos \left(\frac{k-1}{I_{N}-1} \pi\right)\right) \frac{\left(x^{1}-x^{0}\right)}{2}+x^{0}, k=1,2, \ldots, I_{N} \text { for } x \in\left[x^{0}, x^{1}\right]
$$

$I_{N}$ being the total number of sampling points assumed for discretization along the $x$-direction.

According to the GDQ method, we can write the numerical problem in a compact matrix form where we separate the domain and the boundary degrees of freedom. The stability equations and boundary conditions take the following form:

$$
\left[\begin{array}{ll}
{\left[A_{b b}\right]} & {\left[A_{b d}\right]} \\
{\left[A_{d b}\right]} & {\left[A_{d d}\right]}
\end{array}\right]\left\{\begin{array}{l}
d_{b} \\
d_{d}
\end{array}\right\}+\Delta T\left[\begin{array}{cc}
0 & 0 \\
{\left[A_{g_{1}}\right]} & {\left[A_{g_{2}}\right]}
\end{array}\right]\left\{\begin{array}{l}
d_{b} \\
d_{d}
\end{array}\right\}=0
$$

where the subscripts ' $d$ ' and ' $b$ ' refer to the domain and to the boundary, respectively. After a mathematical manipulation, the critical buckling load of the FG wavy CNT stiffened cylindrical shell reads

$$
\left[\left[A_{d d}\right]-\left[A_{d d}\right]\left[A_{b b}\right]^{-1}\left[A_{b d}\right]\right]\left\{d_{d}\right\}+\Delta T\left[\left[A_{g_{2}}\right]-\left[A_{g_{1}}\right]\left[A_{b b}\right]^{-1}\left[A_{b d}\right]\right]=0
$$

In what follows we analyze the thermal buckling of the nanocomposite stiffened cylindrical shells reinforced by wavy CNTs with temperature-dependent (TD) properties at different temperatures. The cylindrical shell is subjected to an initial uniform temperature of $300 \mathrm{~K}$, which is increased gradually.

A linear buckling analysis is carried out to determine the critical temperature at which the cylindrical shell buckles under the thermal loading. The critical temperature $T_{c r}$ is initially determined for temperature-independent (TI) material properties. This critical temperature $T_{c r}$ is expected to change above the initial stress free temperature of $300 \mathrm{~K}$. A varying initial temperature, however, would change the Young's modulus and linear coefficient of thermal expansion of the constituent materials. Thus, it is more appropriate to determine the critical temperature for temperature-dependent (TD) material properties. In the last case, the solution of TD equations is not straightforward but can be simplified substantially by adopting a numerical approach and iterative algorithms, as proposed here for the computation of the buckling load for FG-CNTRC stiffened cylindrical shells.

The analysis is developed through the following steps:

(1) The buckling analysis is carried out for material properties at ambient temperature of $300 \mathrm{~K}$ (i.e., $\Delta T=0)$, and the critical temperature $\Delta T_{c r}^{1}$ is determined at the first step;

(2) The material properties are updated at the increased temperature of $300 \mathrm{~K}+\Delta T_{c r}^{1}$. The buckling analysis is carried out with these new properties, and a new value of critical temperature $\Delta T_{c r}^{2}$ is determined;

(3) Step 2 is repeated systematically until $\left|\Delta T-\Delta T^{k}\right| \leq 0.0001$ and the solution converges to the critical temperature with TD material properties.

\section{Numerical Results}

The numerical results are compared with the main predictions from the available literature in order to demonstrate the performance of the proposed approach. Table 1 summarizes the results in terms of critical thermal load for an isotropic cylindrical shell with different thickness ratios $h / R$ and subjected to a uniform temperature rise. A twofold material is assumed for numerical computations, as found in [71]; namely, a pure metal (i.e., an Aluminum) with Young's modulus of $70 \mathrm{GPa}$, Poisson's ratio 0.3 , and coefficient of thermal expansion $23 \times 10^{-6}$, as well as a pure ceramic (i.e., an Alumina) with Young's modulus of $380 \mathrm{GPa}$, Poisson's ratio 0.3 , and coefficient of thermal expansion $7.4 \times 10^{-6}$. As visible from Table 1, the results based on the proposed formulation resemble quite well those 
predicted in [70]. This demonstrates the accuracy of the GDQ-based solutions of the problem. More in detail, predictions by Mirzavand and Eslami [71] are always more conservative compared to our results, whereas a clear increase of the critical thermal load can be observed for increasing $h / R$ ratios.

Table 1. Thermal buckling $\Delta T_{c r}$ as predicted by the present work and [71] for a uniform temperature rise and $L / R=1$.

\begin{tabular}{cccc}
\hline $\boldsymbol{h} / \boldsymbol{R}$ & Method & Pure Metal (Aluminum) & Pure Ceramic (Alumina) \\
\hline \multirow{2}{*}{0.003} & Present & 55.1114 & 171.2921 \\
& {$[71]$} & 52.1867 & 181.375 \\
\hline \multirow{2}{*}{0.005} & Present & 91.7741 & 285.2439 \\
& {$[71]$} & 90.8012 & 289.537 \\
\hline \multirow{2}{*}{0.007} & Present & 128.4551 & 399.2525 \\
& {$[71]$} & 124.447 & 402.683 \\
\hline \multirow{2}{*}{0.01} & Present & 182.6926 & 567.8284 \\
& {$[71]$} & 187.33 & 597.253 \\
\hline \multirow{2}{*}{0.012} & Present & 219.6345 & 682.6477 \\
& {$[71]$} & 216.007 & 688.039 \\
\hline \multirow{2}{*}{0.015} & Present & 273.1372 & 848.9400 \\
& {$[71]$} & 268.953 & 862.72 \\
\hline
\end{tabular}

Another parametric investigation is performed for a FGM cylindrical shell, where the outer surface is metal-rich, and the inner surface is ceramic-rich (Ti-6Al-4V/ $\left.\mathrm{ZrO}_{2}\right)$. The material properties in terms of Young's modulus and thermal expansion coefficient, are expressed as a nonlinear function of temperature, as suggested in [72]. Table 2 reports the thermal buckling loads $T_{c r}$ (expressed in K) for the simply supported FGM cylindrical shells with different values of volume fraction index $P$, and subjected to a uniform temperature rise.

Table 2. Buckling temperatures $T_{c r}$ (in K) as computed by the Generalized Differential Quadrature (GDQ) approach, compared to predictions by $[73,74]$ for a Functionally Graded Material (FGM) cylindrical shell, with temperature-dependent (TD) or temperature-independent (TI) material properties considering $H=1 / 400$ and $L^{2} / H=300$.

\begin{tabular}{cccc}
\hline$p$ & Method & TD & TI \\
\hline \multirow{4}{*}{0.2} & Present & 354.5263 & 363.8471 \\
& {$[73]$} & 365.0509 & 378.5620 \\
& {$[74]$} & 353.7 & - \\
\hline \multirow{2}{*}{0.5} & Present & 360.8525 & 371.0475 \\
& {$[73]$} & 372.6016 & 387.4075 \\
& {$[74]$} & 360.119 & - \\
\hline \multirow{2}{*}{1} & Present & 369.8812 & 380.9365 \\
& {$[73]$} & 383.4589 & 399.5912 \\
& {$[74]$} & 368.785 & - \\
\hline \multirow{2}{*}{2} & Present & 384.4789 & 395.7673 \\
& {$[73]$} & 401.2534 & 417.9189 \\
& {$[74]$} & 383.244 & - \\
\hline \multirow{2}{*}{3} & Present & 395.9562 & 406.1519 \\
& {$[73]$} & 415.4941 & 430.7708 \\
& {$[74]$} & 394.319 & - \\
\hline & Present & 413.3029 & 419.3226 \\
& {$[73]$} & 437.9041 & 447.0620 \\
& {$[74]$} & 411.669 & - \\
\hline
\end{tabular}


The numerical analysis is repeated for TD and TI material properties, while evaluating the accuracy of our results with respect to the ones predicted in $[73,74]$. Based on this comparative evaluation, our results shows a very good agreement with estimations by $[73,74]$, and fall always between a range of values whose lower limit is determined by [74] and the upper limit is determined by [73], respectively. As also visible in Table 2, the thermal buckling load seems to increase with the CNT volume fraction $p$. These results could be interestingly applied for practical design purposes.

In addition, we evaluate the effect of some mechanical and geometry parameters on the thermal buckling load $\Delta T_{c r}$ of CNTCR stiffened cylindrical shells reinforced by FG wavy CNTs, and subjected to a uniform temperature rise. More specifically, we study the possible effects on the critical thermal buckling load related to different distributions of CNTs within the material, to the presence of ring and stringer stiffeners, to different aspect ratios $A_{R}$, as well as to different waviness indexes $w$ and volume fractions $V_{C N T}^{*}$.

A first investigation considers a cylindrical shell with $L / R=1$, and $R / h=200$, which is made by TI and TD material properties. The numerical results obtained in terms of thermal buckling load are listed in Tables 3 and 4 under the assumptions of: TI and TD material properties, respectively, complete absence of ring and stringer stiffeners (i.e., $N_{r}=N_{s}=0$ ), $A_{R}$ varying from 50 up to 1000, and varying waviness index (i.e., $w=0$, and $w=0.425$ ).

Table 3. Critical thermal buckling load for different distributions of the CNTs within the structure made of TI material properties considering $L / R=1, R / h=200, N_{r}=0, N_{S}=0$.

\begin{tabular}{|c|c|c|c|c|c|}
\hline \multirow{2}{*}{ Profiles } & \multirow{2}{*}{$A_{R}$} & \multicolumn{2}{|c|}{$V_{C N T}^{*}=0.12$} & \multicolumn{2}{|c|}{$V_{C N T}^{*}=0.28$} \\
\hline & & $w=0$ & $w=0.425$ & $w=0$ & $w=0.425$ \\
\hline \multirow{4}{*}{$\wedge$-profile } & $A_{R}=50$ & 355.6195 & 409.7686 & 346.9656 & 446.356 \\
\hline & $A_{R}=100$ & 342.6400 & 407.8564 & 338.9678 & 447.5867 \\
\hline & $A_{R}=500$ & 336.1531 & 404.8622 & 334.6581 & 448.6354 \\
\hline & $A_{R}=1000$ & 335.5539 & 404.3232 & 333.9651 & 448.7409 \\
\hline \multirow{4}{*}{$X$-profile } & $A_{R}=50$ & 375.9555 & 413.1924 & 366.8814 & 450.1936 \\
\hline & $A_{R}=100$ & 356.2644 & 409.7816 & 351.3718 & 449.1031 \\
\hline & $A_{R}=500$ & 344.5911 & 404.1034 & 343.0042 & 446.3097 \\
\hline & $A_{R}=1000$ & 343.5005 & 403.1505 & 342.1739 & 445.7818 \\
\hline \multirow{4}{*}{ O-profile } & $A_{R}=50$ & 356.0734 & 406.7710 & 343.8665 & 431.8363 \\
\hline & $A_{R}=100$ & 341.6468 & 404.8307 & 335.4600 & 432.9287 \\
\hline & $A_{R}=500$ & 334.4003 & 402.2474 & 331.3018 & 432.8269 \\
\hline & $A_{R}=1000$ & 333.7368 & 401.8458 & 330.8940 & 432.7693 \\
\hline \multirow{4}{*}{$U$-profile } & $A_{R}=50$ & 367.6717 & 410.8309 & 358.5940 & 437.8143 \\
\hline & $A_{R}=100$ & 352.3555 & 408.3589 & 344.8158 & 437.9515 \\
\hline & $A_{R}=500$ & 341.3101 & 405.0617 & 336.4925 & 437.7304 \\
\hline & $A_{R}=1000$ & 340.1902 & 404.5425 & 335.6926 & 437.6768 \\
\hline \multirow{4}{*}{ Sigmoidal-profile } & $A_{R}=50$ & 384.5763 & 401.4333 & 375.2713 & 412.1084 \\
\hline & $A_{R}=100$ & 366.8624 & 397.5881 & 357.3245 & 411.5575 \\
\hline & $A_{R}=500$ & 354.0331 & 391.1778 & 347.7359 & 408.1837 \\
\hline & $A_{R}=1000$ & 352.8324 & 390.1325 & 346.8347 & 407.5554 \\
\hline
\end{tabular}


Table 4. Critical thermal buckling load for different distributions of the CNTs within the structure made of TD properties considering $L / R=1, R / h=200, N_{r}=0, N_{s}=0$.

\begin{tabular}{cccccc}
\hline \multirow{3}{*}{ Profiles } & \multirow{2}{*}{$A_{\boldsymbol{R}}$} & \multicolumn{2}{c}{$V_{\text {CNT }}^{*}=\mathbf{0 . 1 2}$} & \multicolumn{2}{c}{$V_{\text {CNT }}^{*}=\mathbf{0 . 2 8}$} \\
\cline { 2 - 5 } & & $\boldsymbol{w}=\mathbf{0}$ & $\boldsymbol{w}=\mathbf{0 . 4 2 5}$ & $\boldsymbol{w}=\mathbf{0}$ & $\boldsymbol{w}=\mathbf{0 . 4 2 5}$ \\
\hline \multirow{4}{*}{$\wedge$-profile } & $A_{R}=50$ & 350.5315 & 401.0361 & 342.4973 & 433.3668 \\
& $A_{R}=100$ & 338.9949 & 398.8109 & 335.5588 & 433.8537 \\
& $A_{R}=500$ & 333.2777 & 395.5772 & 331.5408 & 434.1682 \\
& $A_{R}=1000$ & 332.7525 & 395.0126 & 330.9463 & 434.1723 \\
\hline \multirow{4}{*}{ X-profile } & $A_{R}=50$ & 367.6339 & 403.9401 & 358.4562 & 436.5301 \\
& $A_{R}=100$ & 350.0884 & 400.3097 & 345.5374 & 434.9102 \\
& $A_{R}=500$ & 340.1044 & 394.5435 & 338.5318 & 431.6631 \\
& $A_{R}=1000$ & 339.1756 & 393.5870 & 337.8357 & 431.0726 \\
\hline \multirow{4}{*}{ O-profile } & $A_{R}=50$ & 350.8708 & 398.4375 & 339.8652 & 420.952 \\
& $A_{R}=100$ & 338.0843 & 396.1992 & 332.5311 & 421.3494 \\
& $A_{R}=500$ & 331.6981 & 393.3625 & 328.9072 & 420.6853 \\
& $A_{R}=1000$ & 331.1157 & 392.9302 & 328.5520 & 420.5504 \\
\hline \multirow{5}{*}{ Sigmoidal-profile } & $A_{R}=50$ & 360.7792 & 401.5390 & 352.3864 & 425.8502 \\
& $A_{R}=100$ & 347.2884 & 398.8054 & 340.2270 & 425.4899 \\
& $A_{R}=500$ & 337.3306 & 395.3611 & 333.1242 & 424.8383 \\
& $A_{R}=1000$ & 336.3705 & 394.8309 & 332.4403 & 424.7290 \\
\hline & $A_{R}=100$ & 359.9199 & 390.0668 & 351.1715 & 402.9769 \\
& $A_{R}=500$ & 348.5575 & 383.5699 & 342.9259 & 399.2144 \\
& $A_{R}=1000$ & 347.5143 & 382.5242 & 342.1573 & 398.5467 \\
\hline
\end{tabular}

As visible from Tables 3 and 4, it is worth noticing that the thermal buckling load of nanocomposites with straight CNTs (i.e., $w=0$ ), features a monotone decrease for increasing values of $V_{C N T}^{*}$ and $A_{R}$. Differently, nanocomposites with wavy CNTs (i.e., $w=0.425$ ) exhibit an increasing buckling temperature for an increasing $V_{C N T}^{*}$ and a decreasing $A_{R}$. A clear increase in the buckling temperature is visible moving from straight CNTS to wavy CNTs, or equivalently by comparing the results for $w=0$, and $w=0.425$, as well as for fixed values of $A_{R}, V_{C N T}^{*}$ and fixed profiles. A meaningful effect on the thermal buckling behavior of the structure is also related to the different distributions of CNTs within the nanocomposite. A sigmoidal profile seems to yield to the most conservative results, at least for wavy CNTs, both for TI and TD material properties, whereas the highest results are reached for an asymmetric $\wedge$-distribution. Based on a comparative evaluation of the results in Tables 3 and 4, it is clearly visible as TD material properties yield always to more conservative buckling temperatures, for the same distributions, as well as for fixed $A_{R}, w$, and $V_{C N T}^{*}$. This underlines the great importance of considering the actual geometry and distribution of CNTs within a nanocomposite structure.

A second parametric investigation considers the influence of the $R / h$ geometrical ratio on the thermal buckling load, for different CNT profiles, and the double condition of TI and TD material properties. Figures 3 and 4 show the numerical plots of $\Delta T_{c r}$ vs. $R / h$, as obtained for a fixed $L / R=2$, $V_{C N}^{*}=0.17, A_{R}=1000$, and for two different waviness indexes $w=0$, and $w=0.425$, respectively. As visible from Figures 3 and 4, all the curves obtained for TD materials properties lie always below those ones based on TI material properties, independent of the selected distribution. Moreover, the critical thermal buckling load $\Delta T_{c r}$ decreases monotonically for increasing $R / h$ ratios, reaching the lowest estimations for a symmetric $O$ - distribution or a sigmoidal distribution, depending on whether straight $(w=0)$ or wavy $(w=0.425)$ CNTs are dispersed within the nanocomposite. 


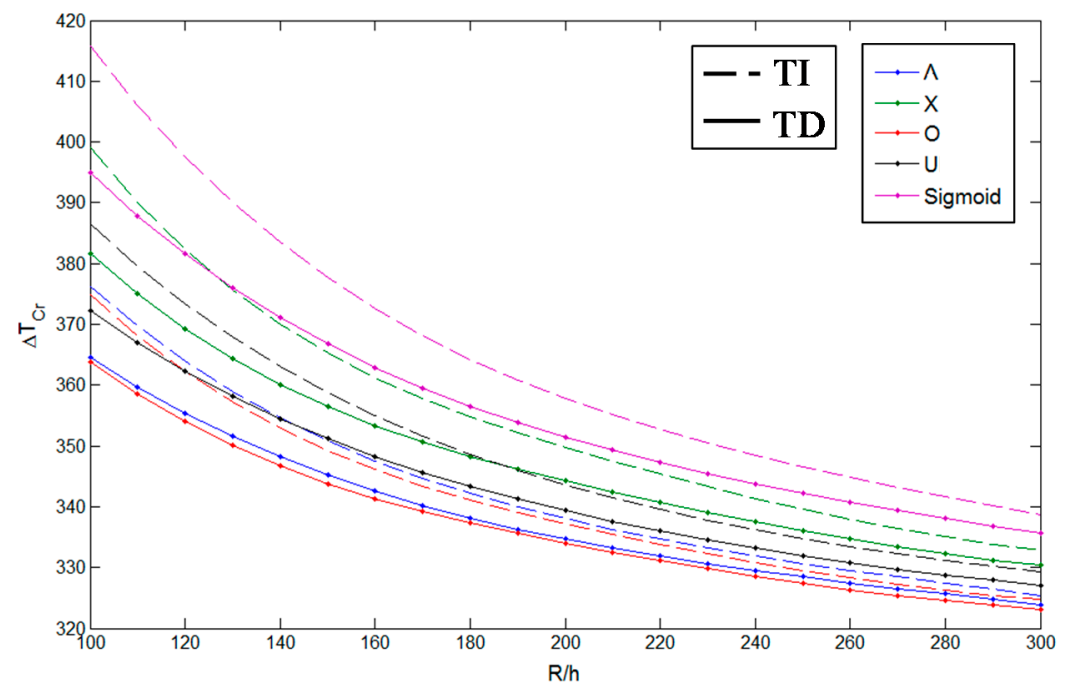

Figure 3. Effect of different CNT profiles on the critical thermal buckling load considering $L / R=2, V_{C N T}^{*}=0.17, A_{R}=1000, w=0, N_{r}=N_{s}=0$. TI: temperature-independent; TD: temperature-dependent.

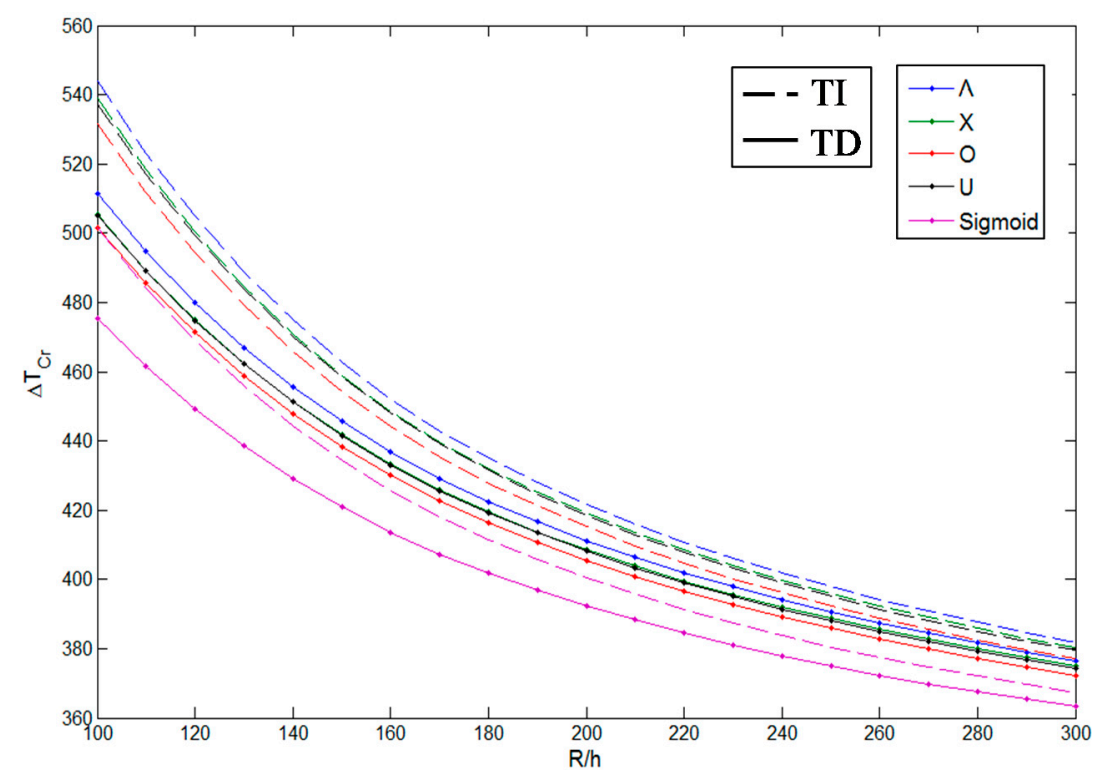

Figure 4. Effect of different CNT profiles on the critical thermal buckling load considering $L / R=2$, $V_{C N T}^{*}=0.17, A_{R}=1000, w=0.425, N_{r}=N_{s}=0$.

Figure 5a-e also represent the variation of the thermal buckling load $\Delta T_{c r}$ vs. $R / h$ for different distributions of straight CNTs within the thickness and for increasing aspect ratios $A_{R}$ from 50 up to 1000. A clear reduction of the thermal buckling load is always reached for increasing aspect ratios, such that, for each given distribution and aspect ratio $A_{R}=50$ we obtain the highest curves, while obtaining the lowest estimations for $A_{R}=1000$. Once again, buckling temperatures based on TD material properties are always more conservative that predictions based on TI material properties, independently of the $A_{R}$. 


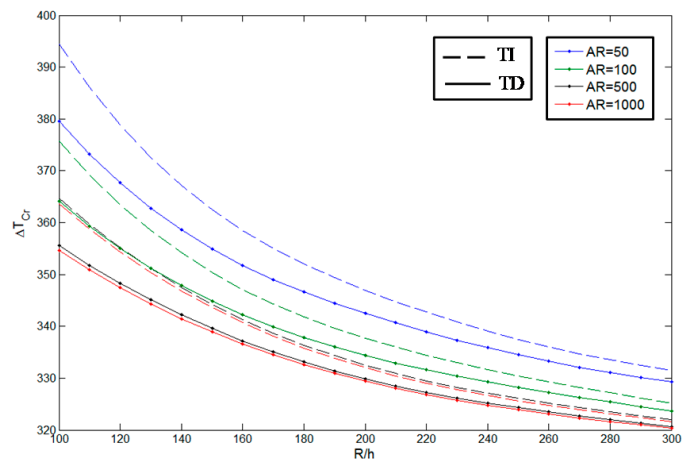

(a) $\wedge$-profile

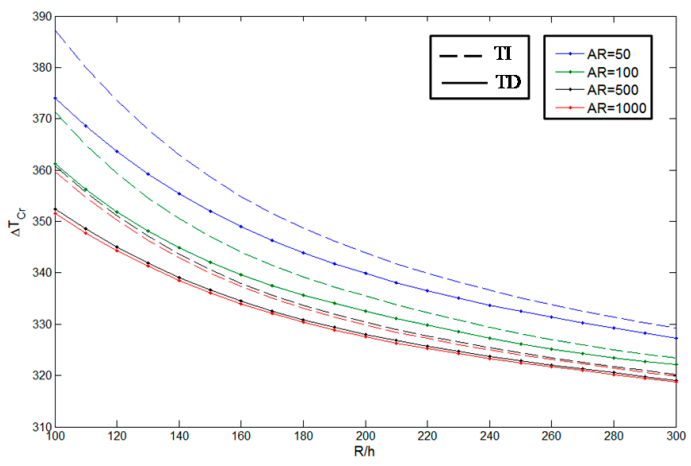

(c) $O$-profile

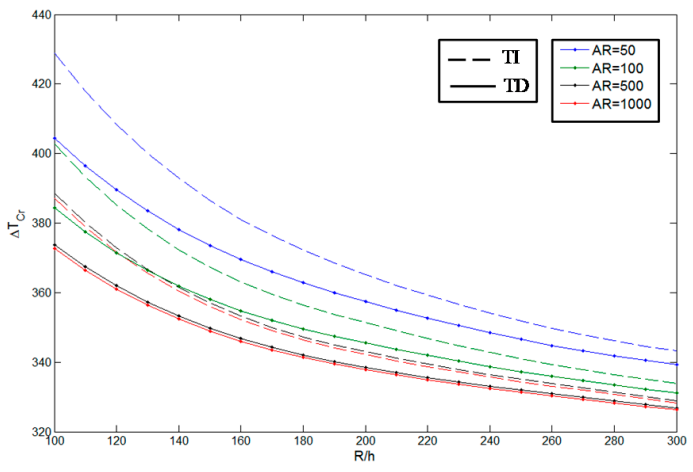

(b) $X$-profile

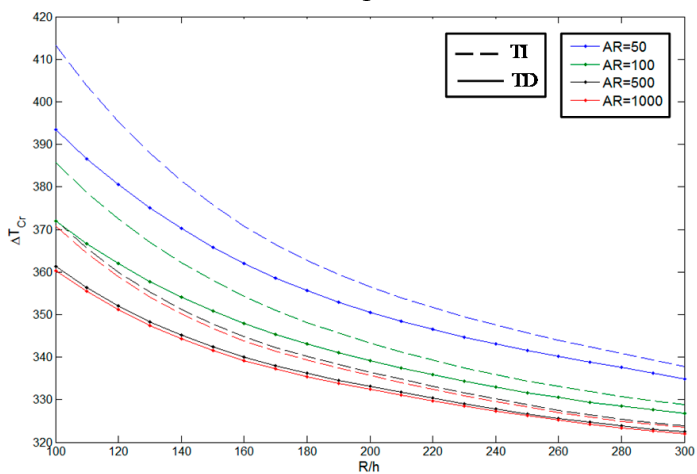

(d) $U$-profile

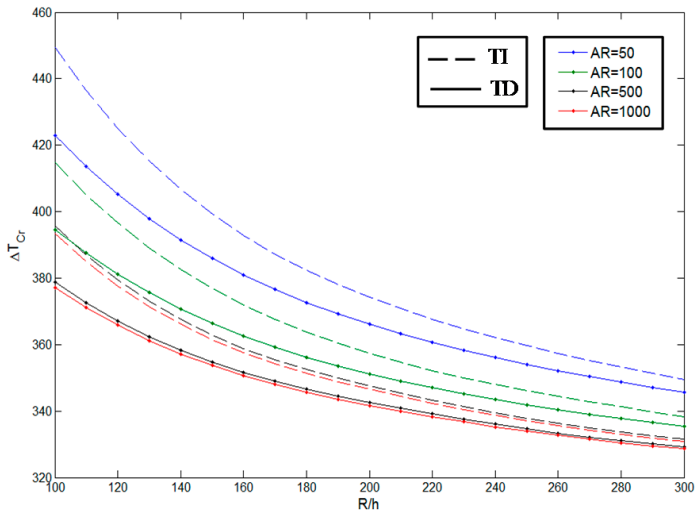

(e) Sigmoidal-profile

Figure 5. $\Delta T_{c r}$ vs. $R / h$ for different aspect ratios $A_{R}$ considering $L / R=2, V_{C N T}^{*}=0.28, w=0$, $N_{r}=N_{s}=0$.

A further systematic investigation is provided to evaluate the influence of wavy CNTs volume fractions $V_{C N T}^{*}$ on the thermal buckling load of the cylindrical shell. Three increasing values are here assigned to the $V_{C N T}^{*}$, namely, $0.12,0.17,0.28$, while considering the double possibility of TI and TD material properties. Figure 6a-e depict all the curves in terms of $\Delta T_{c r}$ vs. $R / h$, for each distribution and $V_{C N T}^{*}$ previously mentioned, and for fixed values of $L / R=2, A_{R}=500$, and $w=0.425$. Interestingly, an increased value of $V_{C N T}^{*}$ causes a considerable increase of the critical thermal buckling load, whose entity varies with the selected pattern of CNTs within the structures, as well as with the selected TI or TD material properties. 


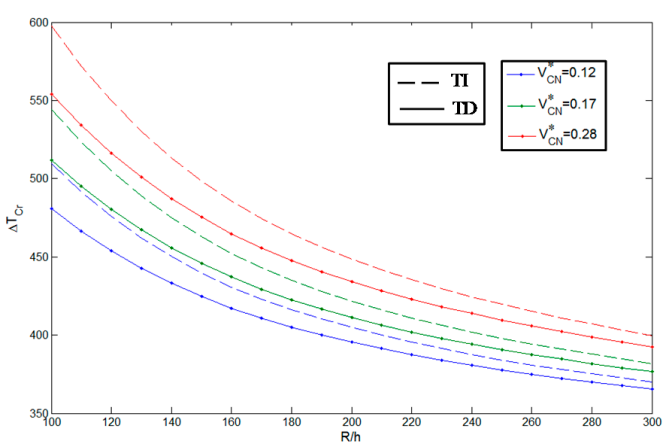

(a) $\wedge$-profile

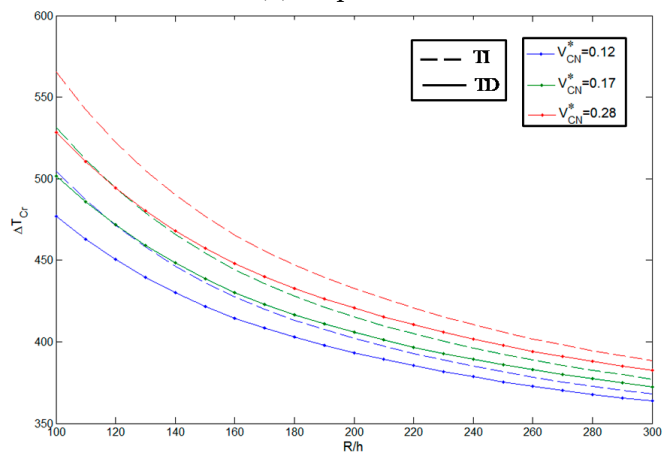

(c) $O$-profile

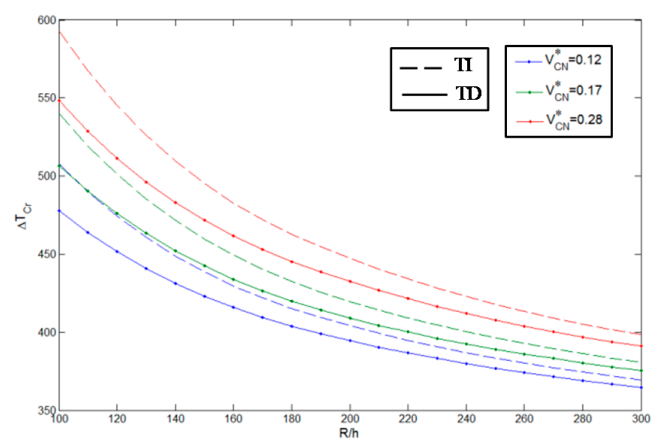

(b) $X$-profile

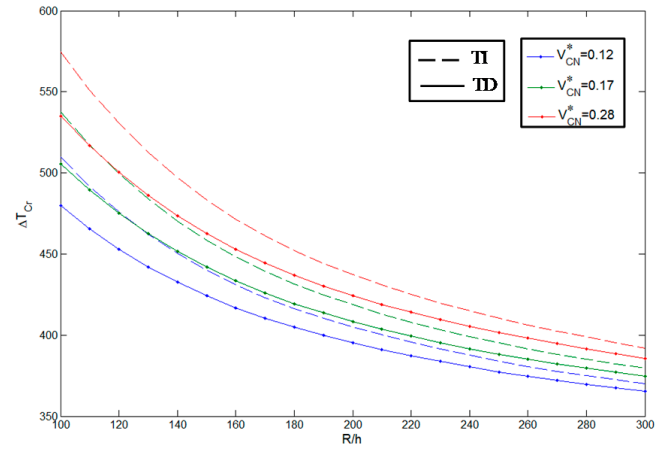

(d) $U$-profile

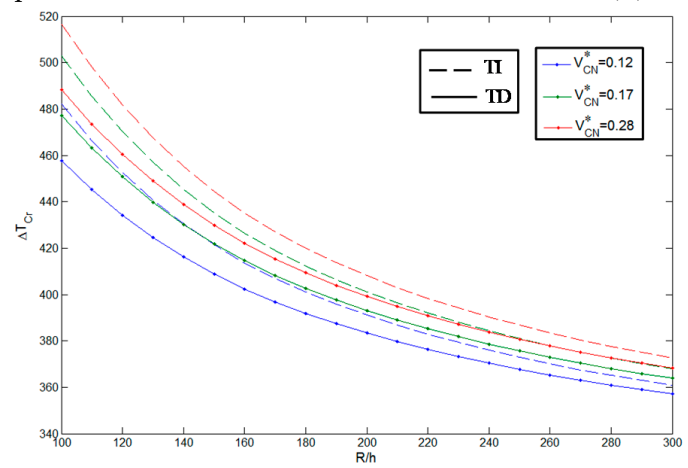

(e) Sigmoidal-profile

Figure 6. $\Delta T_{c r}$ vs. $R / h$ for different volume fractions $V_{C N T}^{*}$ considering $L / R=2, A_{R}=500, w=0.425$, $N_{r}=N_{s}=0$.

For the sigmoidal pattern, we also study how the exponential parameter $s$ can affect the thermal buckling load of the stiffened cylindrical shell reinforced by wavy graded CNTs. This parametric analysis is repeated for different combinations of $A_{R}$ and waviness indexes $w$. According to the plots in Figure $7, \Delta T_{c r}$ decreases for increasing $s$, whose variation is more pronounced for wavy CNTs (more specifically, for $w=0.425$ ), and reverts to a constant value for high values of $s$. This agrees with the sigmoidal trend of Figure 2, where increasing values of $s$ yield to the mechanical behavior of a laminate made by two different laminae and properties. 


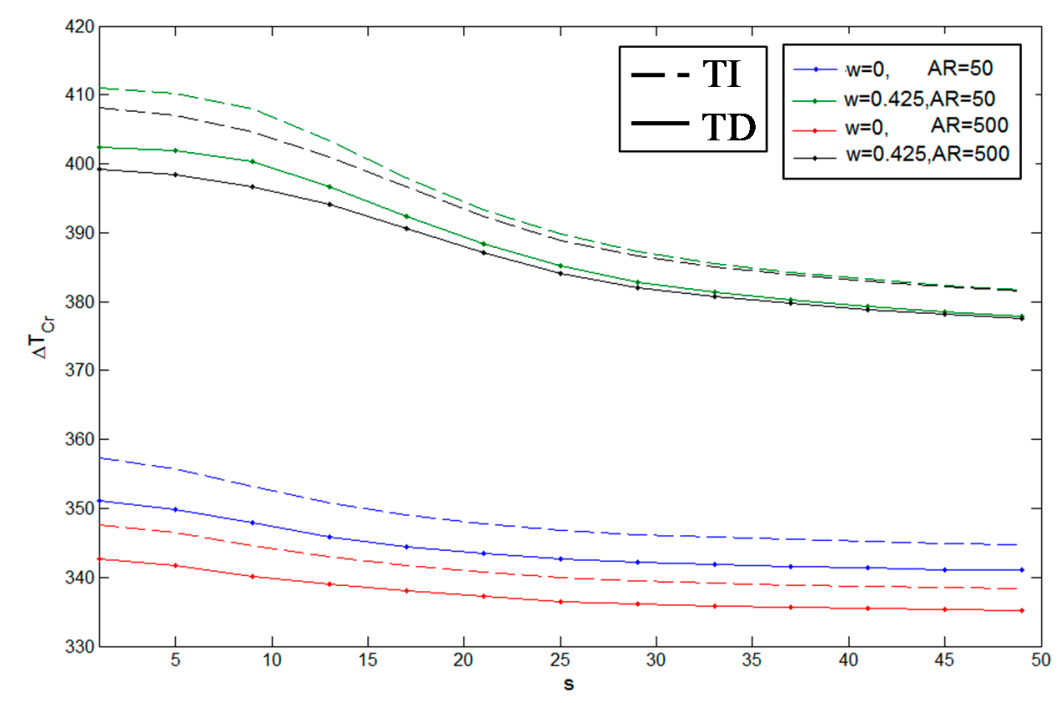

Figure 7. $\Delta T_{c r}$ vs. $s$ for different combinations of aspect ratios $A_{R}$ and waviness indexes $w$ considering $L / R=2, R / h=200, V_{C N T}^{*}=0.28, N_{r}=N_{s}=0$.

The last parametric investigation finally considers the possible presence of ring and/or string stiffeners with a fixed geometry, i.e., $h_{s}=h_{r}=b_{s}=b_{r}=0.004 \mathrm{~m}$. A varying number of ring and/or string stiffeners is assumed at the inner or outer surfaces of the shell, as combined in Table 5 . Based on results listed in Table 5, the critical thermal buckling load for stiffened shells increases significantly compared to the un-stiffened cases, especially when the same number of rings and strings is located at the external surfaces of the cylindrical shell. As also expected, the thermal buckling behavior improves as the number of rings and strings increases. A similar investigation could be repeated for other combinations in terms of stiffener numbers and locations on the structure, but it is here not reported for the sake of brevity. 
Table 5. Effect of the stiffeners on the critical thermal buckling load of the cylindrical shell reinforced by wavy graded CNTs for different profiles considering $L / R=2$, $R / h=200, w=0.425, s=1, A_{R}=1000, V_{C N T}^{*}=0.17$.

\begin{tabular}{|c|c|c|c|c|c|c|c|c|c|c|}
\hline \multirow{2}{*}{$\begin{array}{c}\text { Ring and } \\
\text { Stringer Number }\end{array}$} & \multicolumn{5}{|c|}{ TD } & \multicolumn{5}{|c|}{ TI } \\
\hline & $\wedge$-Profile & $X$-Profile & O-Profile & $U$-Profile & Sigmoidal-Profile & $\wedge$-Profile & $X$-Profile & O-Profile & U-Profile & Sigmoidal-Profile \\
\hline Unstiffened & 411.2273 & 408.5345 & 405.5307 & 408.2149 & 392.371 & 421.7055 & 419.1132 & 415.1666 & 418.5061 & 400.4704 \\
\hline$N_{r}=5$ & 459.2519 & 454.296 & 463.9345 & 460.9213 & 439.7066 & 472.9684 & 468.3331 & 476.1383 & 474.1699 & 450.2883 \\
\hline$N_{S}=5$ & 432.5377 & 430.5091 & 424.9031 & 429.7281 & 409.3133 & 443.834 & 442.0279 & 435.547 & 440.66 & 418.4353 \\
\hline$N_{r}=N_{s}=5$ & 508.4548 & 504.2132 & 515.1755 & 513.4648 & 480.9117 & 515.2078 & 512.2288 & 519.7585 & 519.4056 & 487.7804 \\
\hline$N_{r}=7$ & 468.2045 & 463.572 & 477.4953 & 471.558 & 451.0799 & 482.7139 & 478.9919 & 490.3426 & 487.1171 & 462.3776 \\
\hline$N_{S}=7$ & 441.8178 & 439.6434 & 433.3342 & 438.8732 & 416.2962 & 453.5255 & 451.6761 & 444.2205 & 450.2502 & 425.8656 \\
\hline$N_{r}=N_{s}=7$ & 555.4144 & 553.2414 & 569.8029 & 568.5566 & 520.3784 & 550.762 & 548.6321 & 557.7685 & 557.7418 & 519.8421 \\
\hline$N_{r}=10$ & 480.1307 & 475.8978 & 491.597 & 484.6137 & 464.2851 & 494.8228 & 491.5553 & 505.6045 & 500.4459 & 476.2802 \\
\hline$N_{s}=10$ & 456.9784 & 454.8882 & 446.7671 & 453.9572 & 427.7454 & 468.3527 & 466.4062 & 457.7995 & 465.3265 & 437.6988 \\
\hline$N_{r}=N_{s}=10$ & 595.4563 & 586.3257 & 605.6545 & 604.3793 & 563.6043 & 606.5443 & 606.4783 & 618.9873 & 617.3305 & 571.0981 \\
\hline
\end{tabular}




\section{Conclusions}

This paper presents the thermal buckling analysis of FG wavy CNTRC-stiffened cylindrical shells subjected to a uniform thermal load. An innovative technique known as the GDQ method is here applied to solve the problem numerically while studying the effect of the agglomeration of the reinforcing phase for varying distributions of straight or wavy nanofibers scattered in the matrix and varying volume fraction distributions. Based on a systematical investigation, we verify the sensitivity of the thermal buckling response of the structure to the agglomeration and the shape of CNTs within the matrix to the presence of possible stiffeners at the external surfaces of the structure as well as to some geometry parameters. Such influence is always verified for both temperature-independent (TI) or temperature-dependent (TD) material properties, while verifying the feasibility of the proposed GDQ formulation against the available literature, where possible. Based on the parametric investigation performed in the present work, the thermal buckling load reduces significantly when TD material properties are assumed, and it is strictly related to the selected distribution of CNTs within the matrix. The thermal buckling load also increases in presence of external stiffeners, especially when rings and strings are located together at the inner and outer surfaces of the composite structure. An additional increase of the critical buckling temperature can be reached by adopting wavy CNTs with increasing waviness indexes and decreasing aspect ratios instead of straight CNTs dispersed within the matrix. All these aspects are of extreme importance for practical applications made of nanocomposite materials, especially from a design point of view.

Acknowledgments: The research topic is one of the subjects of the Centre of Study and Research for the Identification of Materials and Structures (CIMEST)-“M. Capurso” of the University of Bologna (Italy).

Author Contributions: Mohammad Nejati, Rossana Dimitri, Francesco Tornabene and Mohammad Hossein Yas contributed equally to the development of the research topic and to the writing of the manuscript.

Conflicts of Interest: The authors declare no conflict of interest. The founding sponsors had no role in the design of the study; in the collection, analyses, or interpretation of data; in the writing of the manuscript, and in the decision to publish the results.

\section{References}

1. Chang, J.S.; Chiu, W.C. Thermal buckling analysis of antisymmetric laminated cylindrical-shell panels. Int. J. Solids Struct. 1991, 27, 1295-1309.

2. Shariyat, M. Thermal buckling analysis of rectangular composite plates with temperature-dependent properties based on a layerwise theory. Thin-Walled Struct. 2007, 45, 439-452. [CrossRef]

3. Dai, H.L.; Zheng, H.Y. Buckling and post-buckling analyses for an axially compressed laminated cylindrical shell of FGM with PFRC in thermal environments. Eur. J. Mech. A/Soild 2011, 30, 913-923. [CrossRef]

4. Ghannadpour, S.A.M.; Ovesy, H.R.; Nassirnia, M. Buckling analysis of functionally graded plates under thermal loadings using the finite strip method. Comput. Struct. 2012, 108, 93-99. [CrossRef]

5. Jinqiang, L.; Yoshihiro, N.; Zhihua, W. The effects of non-uniform temperature distribution and locally distributed anisotropic properties on thermal buckling of laminated panels. Compos. Struct. 2015, 119, 610-619.

6. Bhagat, V.S.; Pitchaimani, J.; Murigendrappa, S.M. Buckling and dynamic characteristics of a laminated cylindrical panel under non-uniform thermal load. Steel Compos. Struct. 2016, 22, 1359-1389. [CrossRef]

7. Katariya, P.V.; Panda, S.K. Thermal buckling and vibration analysis of laminated composite curved shell panel. Aircr. Eng. Aerosp. Technol. 2016, 88, 97-107. [CrossRef]

8. Tauchert, T.R. Thermal buckling of antisymmetric angle-ply laminates. J. Therm. Stress. 1987, 10, $113-124$. [CrossRef]

9. Avci, A.; Sahin, O.S.; Ataberk, N. Thermal buckling behavior of cross-ply hybrid composite laminates with inclined crack. Compos. Sci. Technol. 2006, 66, 2965-2970. [CrossRef]

10. Lee, J. Thermally induced buckling of laminated composites by a layerwise theory. Comput. Struct. 1997, 65, 917-922. [CrossRef] 
11. Matsunaga, H. Thermal buckling of angle-ply laminated composite and sandwich panels according to a global higher-order deformation theory. Compos. Struct. 2006, 72, 177-192. [CrossRef]

12. Baruta, A.; Madencia, E.; Tesslerb, A. Nonlinear thermoelastic analysis of composite panels under non-uniform temperature distribution. Int. J. Solids Struct. 2000, 37, 3681-3713. [CrossRef]

13. Ghomshei, M.M.M.; Mahmoudi, A. Thermal buckling analysis of cross-ply laminated rectangular panels under nonuniform temperature distribution: A differential quadrature approach. J. Mech. Sci. Technol. 2010, 24, 2519-2527. [CrossRef]

14. Spallino, R.; Thierauf, G. Thermal buckling optimization of composite laminates by evolution strategies. Comput. Struct. 2000, 78, 691-697. [CrossRef]

15. Topal, U.; Uzman, U. Thermal buckling load optimization of laminated composite panels. Thin-Walled Struct. 2008, 46, 667-675. [CrossRef]

16. Malekzadeh, P.; Vosoughi, A.; Sadeghpour, M.; Vosoughi, H. Thermal buckling optimization of temperature-dependent laminated composite skew panels. J. Aerosp. Eng. 2014, 27, 64-75. [CrossRef]

17. Setoodeh, S.; Abdalla, M.M.; Ijsselmuiden, S.T.; Gürdal, Z. Design of variable-stiffness composite panels for maximum buckling load. Compos. Struct. 2009, 87, 109-117. [CrossRef]

18. Duong, H.M.; Gong, F.; Liu, P.; Tran, T.Q. Advanced fabrication and properties of aligned carbon nanotube composites: Experiments and modeling. In Carbon Nanotubes-Current Progress of Their Polymer Composites 2016; Berber, M.R., Hafez, I.H., Eds.; InTech: London, UK, 2016; ISBN 978-953-51-2470-2.

19. Natarajan, B.; Lachman, N.; Lam, T.; Jacobs, D.; Long, C.; Zhao, M.; Wardle, B.L.; Sharma, R.; Liddle, J.A. The evolution of carbon nanotube network structure in unidirectional nanocomposites resolved by quantitative electron tomography. ACS Nano 2015, 9, 6050-6058. [CrossRef] [PubMed]

20. Shen, H.S. Nonlinear bending of functionally graded carbon nanotube reinforced composite plates in thermal environments. Compos. Struct. 2009, 91, 9-19. [CrossRef]

21. Shi, D.L.; Feng, X.Q.; Huang, Y.Y.; Hwang, K.C.; Gao, H. The Effect of Nanotube Waviness and Agglomeration on the Elastic Property of Carbon Nanotube-Reinforced Composites. J. Eng. Mater. Technol. ASME 2010, 126, 250-257. [CrossRef]

22. Sobhaniaragh, B.; Barati, A.H.N.; Hedayati, H. Eshelbye-Mori-Tanaka approach for vibrational behavior of continuously graded carbon nanotube-reinforced cylindrical panels. Compos. Part B Eng. 2012, 43, 1943-1954. [CrossRef]

23. Mirzaei, M.; Kiani, Y. Thermal buckling of temperature dependent FG-CNT reinforced composite plates. Meccanica 2016, 51, 2185-2201. [CrossRef]

24. Reddy, J.N. A refined nonlinear theory of plates with transverse shear deformation. Int. J. Solids Struct. 1984, 20, 881-896. [CrossRef]

25. Nejati, M.; Eslampanah, A.H.; Najafizadeh, M.M. Buckling and Vibration Analysis of Functionally Graded Carbon Nanotube-Reinforced Beam under Axial Load. Int. J. Appl. Mech. 2016, 8. [CrossRef]

26. Mohammadzadeh, R.; Najafizadeh, M.M.; Nejati, M. Buckling of 2D-FGCylindrical Shells under Combined External Pressure and Axial Compression. Adv. Appl. Math. Mech. 2013, 5, 391-406. [CrossRef]

27. Suresh, S.; Mortensen, A. Fundamentals of Functionally Graded Materials; The Institute of Materials: London, UK, 1998; LMM-CHAPTER-1998-001.

28. Nejati, M.; Malekzadehfard, K.; Eslampanah, A.H. Effects of fiber orientation and temperature on natural frequencies of a functionally graded beam reinforced with fiber. J. Mech. Sci. Technol. 2015, 29, $33-63$. [CrossRef]

29. Yas, M.H.; Nejati, M.; Asanjarani, A. Free Vibration Analysis of Continuously Graded Fiber Reinforced Truncated Conical Shell via Third-Order Shear Deformation Theory. J. Solid Mech. 2016, 8, 212-231.

30. Nejati, M.; Asanjarani, A.; Dimitri, R.; Tornabene, F. Static and Free Vibration Analysis of Functionally Graded Conical Shells Reinforced by Carbon Nanotubes. Int. J. Mech. Sci. 2017, 130, 383-398. [CrossRef]

31. Nejati, M.; Malekzadehfard, K.; Eslampanah, A.H.; Jafari, S.S. Free Vibration Analysis of Reinforced Composite Functionally Graded Plates with Steady State Thermal Conditions. Lat. Am. J. Solids Struct. 2017, 14, 886-905. [CrossRef]

32. Kandasamy, R.; Dimitri, R.; Tornabene, F. Numerical study on the free vibration and thermal buckling behavior of moderately thick functionally graded structures in thermal environments. Compos. Struct. 2016, 157, 207-221. [CrossRef] 
33. Kamarian, S.; Salim, M.; Dimitri, R.; Tornabene, F. Free vibration analysis conical shells reinforced with agglomerated Carbon Nanotubes. Int. J. Mech. Sci. 2016, 108-109, 157-165. [CrossRef]

34. Fantuzzi, N.; Tornabene, F.; Bacciocchi, M.; Dimitri, R. Free vibration of arbitrarily shaped Functionally Graded Carbon Nanotube-reinforced plates. Compos. Part B Eng. 2017, 115, 384-408. [CrossRef]

35. Tornabene, F.; Fantuzzi, N.; Bacciocchi, M.; Dimitri, R. Free vibrations of composite oval and elliptic cylinders by the generalized differential quadrature method. Thin-Walled Struct. 2015, 97, 114-129. [CrossRef]

36. Tornabene, F.; Fantuzzi, N.; Bacciocchi, M.; Viola, E. Effect of Agglomeration on the natural frequencies of functionally graded carbon nanotube-reinforced laminated composite doubly-curved shells. Compos. Part B Eng. 2016, 89, 187-218. [CrossRef]

37. Tornabene, F.; Fantuzzi, N.; Bacciocchi, M.; Viola, E. Higher-order theories for the free vibration of doubly-curved laminated panels with curvilinear reinforcing fibers by means of a local version of the GDQ method. Compos. Part B Eng. 2015, 81, 196-230. [CrossRef]

38. Liu, G.R.; Wu, T.Y. In-plane vibration analyses of circular arches by the generalized differential quadrature rule. Int. J. Mech. Sci. 2001, 43, 2597-2611. [CrossRef]

39. Kang, K.; Bert, C.W.; Striz, A.G. Vibration analysis of shear deformable circular arches by the differential quadrature method. J. Sound Vib. 1995, 181, 353-360. [CrossRef]

40. Karami, G.; Malekzadeh, P. In-plane free vibration analysis of circular arches with varying cross-sections using differential quadrature method. J. Sound Vib. 2004, 274, 777-799. [CrossRef]

41. De Rosa, M.A.; Franciosi, C. Exact and approximate dynamic analysis of circular arches using DQM. Int. J. Solids Struct. 2000, 37, 1103-1117. [CrossRef]

42. Malekzadeh, P.; Karami, G. Out-of-plane static analysis of circular arches by DQM. Int. J. Solids Struct. 2003, 40, 6527-6545. [CrossRef]

43. Viola, E.; Tornabene, F. Vibration analysis of damaged circular arches with varying cross-section. Struct. Integr. Durab. 2005, 1, 155-169.

44. Tomasiello, S. Differential quadrature method: Application to initial-boundary-value problems. J. Sound Vib. 1998, 218, 573-585. [CrossRef]

45. Maleki, S.; Tahani, M.; Andakhshideh, A. Transient response of laminated plates with arbitrary laminations and boundary conditions under general dynamic loadings. Arch. Appl. Mech. 2011, 82, 615-630. [CrossRef]

46. Hong, C.C. Transient responses of magnetostrictive plates by using the GDQ method. Eur. J. Mech. A/Solid 2010, 29, 1015-1021. [CrossRef]

47. Kurtaran, H. Geometrically nonlinear transient analysis of moderately thick laminated composite shallow shells with generalized differential quadrature method. Compos. Struct. 2015, 125, 605-614. [CrossRef]

48. Tornabene, F.; Dimitri, R.; Viola, E. Transient dynamic response of generally-shaped arches based on a GDQ-time-stepping method. Int. J. Mech. Sci. 2016, 114, 277-314. [CrossRef]

49. Tomasiello, S. Stability and accuracy of the iterative differential quadrature method. Int. J. Numer. Methods Eng. 2003, 58, 1277-1296. [CrossRef]

50. Tomasiello, S. Simulating non-linear coupled oscillators by an iterative differential quadrature method. J. Sound Vib. 2003, 265, 507-525. [CrossRef]

51. Martone, A.; Faiella, G.; Antonucci, V.; Giordano, M.; Zarrelli, M. The effect of the aspect ratio of carbon nanotubes on their effective reinforcement modulus in an epoxy matrix. Compos. Sci. Technol. 2011, 71, 1117-1123. [CrossRef]

52. Reddy, J.N. Mechanics of Laminate Composite Plates and Shell. Theory and Analysis; CRC Press LLC: Boca Raton, FL, USA, 2004.

53. Zhang, L.; Li, X. Buckling and vibration analysis of functionally graded magneto-electro-thermo-elastic circular cylindrical shells. Appl. Math. Model. 2013, 37, 2279-2292.

54. Wang, Z.X.; Shen, H.S. Nonlinear vibration of nanotube-reinforced composite plates in thermal environments. Comput. Mater. Sci. 2011, 50, 2319-2330. [CrossRef]

55. Dung, V.D.; Hoa, K.L. Research on nonlinear torsional buckling and post-buckling of eccentrically stiffened functionally graded thin circular cylindrical shells. Compos. Part B Eng. 2013, 51, 300-309. [CrossRef]

56. Dung, V.D.; Chan, D.Q. Analytical investigation on mechanical buckling of FGM truncated conical shells reinforced by orthogonal stiffeners based on FSDT. Compos. Struct. 2017, 159, 827-841. [CrossRef]

57. Duc, N.D.; Cong, P.H. Nonlinear postbuckling of an eccentrically stiffened thin FGM plate resting on elastic foundations in thermal environments. Thin-Walled Struct. 2014, 75, 103-112. 
58. Duc, N.D.; Cong, P.H. Nonlinear thermal stability of eccentrically stiffened functionally graded truncated conical shells surrounded on elastic foundations. Eur. J. Mech. A/Solid 2015, 50, 120-131. [CrossRef]

59. Ventsel, E.; Krauthammer, T. Thin Plates and Shells: Theory: Analysis and Application; CRC Press: Boca Raton, FL, USA, 2001.

60. Brush, D.O.; Almorth, B.O. Buckling of Bars, Plates and Shells; McGraw-Hill: New York, NY, USA, 1975.

61. Bagherizadeh, E.; Kiani, Y.; Eslami, M.R. Mechanical buckling of functionally graded material cylindrical shells surrounded by Pasternak elastic foundation. Compos. Struct. 2011, 93, 3063-3071. [CrossRef]

62. Shu, C. Differential Quadrature and Its Application in Engineering; Springer Science \& Business Media: London, UK, 2012.

63. Nejati, M.; Yas, M.H.; Eslampanah, A.H.; Bagheriasl, M. Extended three-dimensional generalized differential quadrature method: The basic equations and thermal vibration analysis of functionally graded fiber orientation rectangular plates. Mech. Adv. Mater. Struct. 2017, 24, 854-870. [CrossRef]

64. Tornabene, F.; Fantuzzi, N.; Ubertini, F.; Viola, E. Strong formulation finite element method based on differential quadrature: A survey. Appl. Mech. Rev. 2015, 67, 020801. [CrossRef]

65. Tornabene, F.; Fantuzzi, N.; Bacciocchi, M. Strong and Weak Formulations Based on Differential and Integral Quadrature Methods for the Free Vibration Analysis of Composite Plates and Shells: Convergence and Accuracy. Eng. Anal. Bound. Elem. 2017, in press. [CrossRef]

66. Shu, C.; Richards, B.E. Parallel simulation of incompressible viscous flows by generalized differential quadrature. Comput. Syst. Eng. 1992, 3, 271-281. [CrossRef]

67. Shu, C.; Richards, B.E. Application of generalized differential quadrature to solve two-dimensional incompressible Navier-Stokes equations. Int. J. Numer. Methods Fluids 1992, 15, 791-798. [CrossRef]

68. Quan, J.R.; Chang, C.T. New insights in solving distributed system equations by the quadrature method-I. Analysis. Comput. Chem. Eng. 1989, 13, 779-788. [CrossRef]

69. Bert, C.; Malik, M. Differential quadrature method in computational mechanics. Appl. Mech. Rev. 1996, 49, 1-27. [CrossRef]

70. Shu, C.; Chen, W.; Xue, H.; Du, H. Numerical study of grid distribution effect on accuracy of DQ analysis of beams and plates by error estimation of derivative approximation. Int. J. Numer. Methods Eng. 2001, 51, 159-179. [CrossRef]

71. Mirzavand, B.; Eslami, M.R. Thermal Buckling of Imperfect Functionally Graded Cylindrical Shells Based on the Wan-Donnell Model. J. Therm. Stress. 2006, 29, 37-55. [CrossRef]

72. Shen, H.S. Functionally Graded Materials: Nonlinear Analysis of Plates and Shells; CRC Press: Boca Raton, FL, USA, 2009.

73. Shen, H.S. Thermal postbuckling behavior of functionally graded cylindrical shells with temperature-dependent properties. Int. J. Solids Struct. 2004, 41, 1961-1974. [CrossRef]

74. Sun, J.; Xu, X.; Lim, C.W. Accurate symplectic space solutions for thermal buckling of functionally graded cylindrical shells. Compos. Part B Eng. 2013, 55, 208-214. [CrossRef]

(C) 2017 by the authors. Licensee MDPI, Basel, Switzerland. This article is an open access article distributed under the terms and conditions of the Creative Commons Attribution (CC BY) license (http:/ / creativecommons.org/licenses/by/4.0/). 